九州大学学術情報リポジトリ

Kyushu University Institutional Repository

\title{
Combined-Flow Ripples : Genetic Experiments and Applications for Geologic Records
}

Yokokawa, Miwa

Department of Earth and Space Science, Faculty of Science, Osaka University

https://doi.org/10.5109/1543655

出版情報: 九州大学大学院理学研究院紀要 : Series D, Earth and planetary sciences. 29 (1)，pp.138, 1995-12-26. Faculty of Science, Kyushu University

バージョン :

権利関係: 
Mem. Fac. Sci., Kyushu Univ., Ser. D, Earth Planet. Sci., Vol. XXIX, No. 1, pp. 1-38, text-figs. 1-25, December 25, 1995

\title{
Combined-Flow Ripples : Genetic Experiments and Applications for Geologic Records
}

\author{
Miwa YoKoKAWA*
}

\begin{abstract}
Genetic experiments on combined-flow ripples were carried out to provide detailed criteria of combined-flow ripples. A recirculating flume with a wave generator was used, in which the direction of unidirectional flows was reversible. Two types of combined-flow ripples, wave-dominated and current-dominated types, were recognized based on the ripple roundness. The current-dominated combined-flow ripples appeared when the unidirectional velocity exceeded approximately $19 \mathrm{~cm} / \mathrm{sec}$ independent from unidirectional-flow direction. Ripple symmetry index (RSI) and ripple roundness index (RRI) were useful for distinction of combined-flow ripples from either current or wave ripples. The indicative features of combined-flow ripples were revealed as follows: (1) rounded lee and stoss sides, and also rounded troughs were remarkable within the currentdominated combined-flow ripples. The roundness became stronger as relative magnitude of oscillatory velocity to unidirectional velocity became lower; (2) the internal structures were characterized by convex-upward foreset laminae, the extremely sigmoidal shape of toes, a "joined" structure and truncated troughs, for current-dominated combined-flow ripples. Some of these were recognized in wavedominated combined-flow ripples, although whose outer forms were very close to that of wave ripples; and (3) the character of the grain fabric of combined-flow ripples was that preferred imbrication pattern both of the wave-ripple-type and the current-ripple-type appeared in specific locality in a single foreset lamina. The unique round profiles of combined-flow ripples resulted from the characteristic movement of sand particles on migrating ripples. The vortices generated only beside lee sides of the ripples, caused by the coexistence of oscillatory and unidirectional components.

The experimental results were applied to geologic records to prove those criteria available for the distinction of combined-flow ripples from wave and current ripples, and the estimation of sedimentary processes. The applications were carried out as follows: (1) distinction of wave ripples and combined-flow ripples in shoreface deposits; (2) identification of combined-flow ripples in tidal deposits; (3) examination of coarse-grained ripples in shoreface deposits; (4) examination of ripples within 'hummocky sequences'; and (5) paleo-current
\end{abstract}

Manuscript received September 28, 1995; accepted October 9, 1995

* Department of Earth and Space Science, Faculty of Science, Osaka University, Toyonaka, Osaka 560, Japan 
analysis for tide-dominated shelf deposits including combined-flow ripples of the Miocene Shirahama Formation in the Kii Peninsula, Japan. The most powerful criterion for the distinction was the "rounded profile" of the ripple, i.e., high RRI value. The characteristic internal structures were also useful. Wave-dominated combined-flow ripples were sometimes difficult to distinguish from wave ripples only by their outer forms. The recognition of the combined-flow ripples in 'hummocky sequences' may strongly indicate the process of HCS formation, which is still a matter of controversy.

\section{Introduction}

Combined waves and currents, combined flows, have come to the attention of sedimentologists (e.g., SWIFT et al., 1983; AlLEN, 1985; NotTVEDT and KREISA, 1987; MYROW and SOUTHARD, 1991; DUKE et al., 1991), during the debate on the sedimentary process of hummocky cross-stratification. Combined flows are commonly generated both in the continental shelves and nearshore settings during storms (e.g., MurRay, 1970; BEARdSlEy and Butman, 1974; NiEdorodA and SWIFT, 1981), and in tide-influenced environments (e.g., REINECK and SINGH, 1980; CARLING, 1981). On stormy shorefaces and the continental shelves, storm ebb surges act with waves. On tidal flats, tidal inlets, and tide-dominated shelves, tidal currents act with waves. There are numerous theoretical works on combined flows by coastal and hydraulic engineers (after SWAN, 1990). Experimental studies on the dynamics of combined flows (e.g., GRANT and MUDSEN, 1979; BREVIK and AAS, 1980; SWAN, 1990) have been carried out, but experiments on combined-flow generated bed configurations are scarce.

INMAN and BOWEN (1963) examined sand transport in the formation of combined-flow rippled beds. HARMS (1969) was the first and only one to provide an experimental description of combined-flow ripples. In his experiments, currents and waves moved in the same direction. This setting is, as stated by himself, insufficient to discuss the characteristics of combined-flow ripples. Based on the results of the experiment, some criteria have been provided for combined-flow ripples such as rounder crests with asymmetric profiles and a relatively continuous crest. The internal structures of combined-flow ripples were described as tangential to the lower bounding surface and inclined in the downcurrent direction (HARMS et al., 1975). These are the only criteria for combined-flow ripples obtained until now (HARMS et al., 1982). On the other hand, ARNOTT and SOUTHARD (1990) have carried out experiments with a U-shaped duct concentrated on higher velocity and a longer oscillation period, taking aim at hummocky beds. The unidirectional velocity, however, was relatively low (up to 25 $\mathrm{cm} / \mathrm{sec}$ ) in their experiments. MASUDA and YoKOKAWA (1992, 1993) have preliminary reported the characteristic profiles of combined-flow ripples prior to the present study.

In the modern environments such as tidal flats and coasts, combined-flow ripples have been known by their characteristic outer forms (e.g., REINECK and SINGH, 1980; ALLEN, 1982), and have been called "asymmetric wave-formed ripple marks" (TANNER, 1967), "combined-flow ripples" (HARMS, 1969), "transverse combined current/wave ripples" (REINECK and SINGH, 1980), and "wave-current 
ripple marks" (ALLEN, 1982). WUNDERLICH (1970) described "asymmetrical oscillation ripples" from Devonian tidal deposits, and used them as indices for the emergence, based on his observations at the North Sea tidal flats. Regarding to storm deposits, ripples which appear in a uppermost part of a 'hummocky sequence' have been pointed out as combined-flow ripples (DOTT and BOURGEOIS, 1982; NøTTVEDT and KREISA, 1987). These are based on the description of HARMS (1969). MYROW (1992) described combined-flow ripples from the tempestites in shelf deposits based on the experiments of ARNOTT and SOUTHARD (1990), and this may be the first to distinguish clearly combined-flow ripples from wave ripples. JENNETTE and PRYOR (1993) described coarse-grained asymmetrical ripples in storm deposits as products of combined flows based on their asymmetric profiles and unidirectional dipping foreset laminae. Although there have been many photographs or drawings of the ripples which can be recognized as combined-flow ripples from some environments such as tidal flats (e.g., TANKARD and HOBDAY, 1977; VOS and ERICKSSON, 1977), lagoons (e.g., SINGH, 1980), stormy shorefaces (e.g., KATSURA et al., 1985) and even deep seas (e.g., SHIPECK, 1962), almost all of them were loosely interpreted as wave ripples. It seems as though there is little understanding of the significance of recognition of combined-flow ripples. Perhaps one of the reasons for this confusion is a shortage of experimental works and criteria on combined-flow ripples.

In the present study, the author first carried out genetic experiments of combined-flow ripples to provide detailed criteria for the genesis of combinedflow ripples. A recirculating flume with a wave generator, in which the direction of unidirectional flows was reversible and could be run in the same direction or in the opposite direction as the wave propagation, was used. The latter set up has not been used in the previous works, and is more similar to the situations both in stormy shorefaces and tidal flats than in the HARMS' (1969) experiment. The conditions of these experiments covered those parts that had been left behind the experiments by both HARMS (1969) and ARNOTT and SOUTHARD (1990). The present experiments derived results on formative conditions, internal structures, grain fabrics and sand movements with regard to the characteristic profiles of combined-flow ripples. These results were then applied to geologic records to prove those criteria available for discrimination of combined-flow ripples from wave and current ripples.

\section{Genetic Experiments of Combined-Flow Ripples}

\subsection{Experimental Apparatus and Methods}

\subsubsection{Experimental apparatus}

The recirculating flume (Department of Earth and Space Science, Faculty of Science, Osaka University) using in this experiment is $10 \mathrm{~m}$ long, $0.2 \mathrm{~m}$ wide, and $0.5 \mathrm{~m}$ deep, with glass side walls. The flume is fixed horizontally. A plunger-type wave generator is installed at one end of the flume, and a wave absorber is placed at the other end (Fig. 1). With this in place the reflection coefficient is very small, and this absorber also plays a role of flow straightener. The pipeworks can be reversed so that the unidirectional flows superimpose on the waves in two ways. First, the current travels in the direction opposite the wave propagation, 


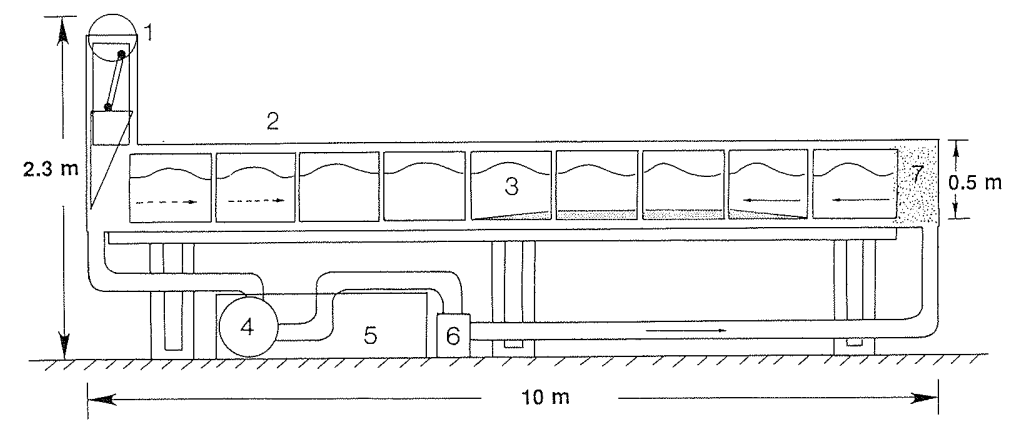

Fig. 1. Recirculating flume equipped with a wave generator. 1: wave generator, 2: flume, 3: glass window, 4: pump, 5: water tank, 6: flow meter, 7: wave energy absorber. Solid arrows show unidirectional flow direction, and dashed arrows show wave prograding direction. Direction of unidirectional flow is reversible by replacing the pipeworks.

constituting a co-flowing "adverse" current. Second, the current follows the same direction as the wave propagation, and constitutes a co-flowing "favorable" current. For ease of discussion, the end of the flume where the wave generator is mounted will be designated as "offshore", and the other downwave end as "onshore". The terms "upcurrent" and "downcurrent" relate to the unidirectional component of flow.

The present experiments considered purely unidirectional flows, purely oscillatory flows and two kinds of combined flows. The maximum unidirectional velocity was $44.4 \mathrm{~cm} / \mathrm{sec}$, whereas the maximum oscillatory velocity was 30.6 $\mathrm{cm} / \mathrm{sec}$. Unidirectional velocity was measured through the window by tracing neutrally buoyant particles, which float a few centimeters above the bed. Oscillatory velocity was calculated as an orbital velocity based on wave period, wave height, wavelength and water depth. For combined flows, the unidirectional and oscillatory components were measured in the same way.

Well-sorted quartz fine sands $(0.18 \mathrm{~mm})$ were mainly used for the experiments, and two additional different grain sizes: coarse silts $(0.06 \mathrm{~mm})$; and medium sands $(0.29 \mathrm{~mm})$ were used for comparison of grain size effects. The sands were heaped into a flat mound, $20 \mathrm{~cm}$ in width and extending between 1 to 5 $\mathrm{m}$ downstream from the onshore end of the flume. The central $2 \mathrm{~m}$ length of the mound was ca. $13 \mathrm{~cm}$ high, sloping gradually to the flume floor on either side (Fig. 1). Each run started with the same initial bed surface, planar and horizontal, on the central $2 \mathrm{~m}$ length of the mound. Flow continued until the bedforms reached a stable state throughout the $2 \mathrm{~m}$ length of the center. Then the profiles of the bedforms were promptly traced and photographed through the glass side wall. The side-wall effects on the shape of the bedforms can be negligible to this discussion.

\subsubsection{Description of ripples and calculation of ripple indices}

Notations for each ripple is defined in this study as Figure 3. Ripple index (RI), ripple symmetry index (RSI), and ripple roundness index (RRI) were calculated from the traces of ripple profiles parallel to the flow (Fig.2). Ripple index (RI) represents the ratio of wave length to wave height of a ripple, and ripple symmetry index (RSI) is the ratio of length of the horizontal projection of 


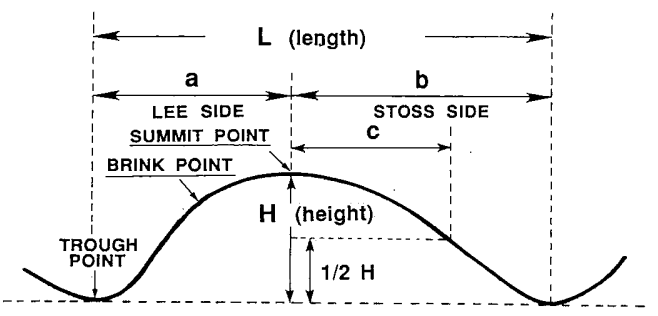

$\mathrm{RI}=\mathrm{L} / \mathrm{H}, \quad \mathrm{RSI}=\mathrm{b} / \mathrm{a}, \quad \mathrm{RRI}=\mathrm{c} / \mathrm{b}$

Fig. 2. A diagram for terms used in describing ripples seen in vertical profiles and ripple indices.

roundness becomes stronger. a stoss side to length of the horizontal projection of a lee side (e.g., TANNER, 1967). The value increases as the asymmetry of ripples becomes stronger. Ripple roundness index (RRI) is newly introduced here as the ratio of the horizontal streamwise distance between the crest and the point on the stoss side representing half the ripple height to the horizontal length of the stoss side. This value increases as the degree of ripple

\subsubsection{Visualization of internal sedimentary structures}

To make combined-flow ripple laminations distinct, silicon carbide abrasives (0.1 - $0.2 \mathrm{~mm}$ in mean diameter) were periodically fed. Silicon carbide abrasives mixed with water were fed with a large syringe held about $10 \mathrm{~cm}$ above the bed in order to avoid disturbing either the migrating ripples or the flows. In order to observe the stacking lamination, quartz sand was supplied to form climbing ripples. For this, a feed hopper that traversed the entire length of the flume was used. Sediment was fed periodically at a constant speed while dropping into the flow a curtain of sediment extending from one wall to the other. Sediment-feed passes were made at intervals of several minutes in order to cover the former surface structure of the ripples. In this case, the silicon carbide abrasives were fed alternately with quartz sand feeding.

\subsubsection{Grain fabric analysis}

Sampling. After the bedform reached a state of equilibrium, oscillatory and unidirectional flows were abruptly stopped at the same time, and the water was drained very slowly so that bedforms would not be destroyed. The sand was half dried up and samples were cut with a knife and taken up as blocks parallel to the flow direction. The knife-cut surfaces were carefully impregnated with quick setting, low-viscosity adhesive ( Aron Alpha", Toagosei Chemical Industry Co., Ltd.). The knife-cut surfaces hardened in a few minutes, becoming hard box-like walls $1-3 \mathrm{~mm}$ in thickness (MASUDA and SUZAKI, 1984; YOKOKAWA and MASUDA, 1988, 1991).

Sand blocks were left to dry under room conditions for several days, and then impregnated completely with resin (Petropoxy 154, Palouse Petro Products). The surfaces of the impregnated samples, which represented the streamwise sections of ripples, were polished with a diamond paste 1 micron in diameter to make them suitable for photomicrographs.

Measurements. Imbrication angles were measured directly from photomicrographs as the direction of the apparent long axis of grains, with the ratio of the long axis to the short axis greater than 3:2. The "least projection elongation", i.e., 
the direction of two parallel lines with minimum separation which can be drawn tangentially to the grain projection (DAPPLES and ROMINGER, 1945), was adopted as the direction of the long axis. The data are shown in rose diagrams whose cell size is 10 degrees.

\subsubsection{Observation of sand particle movement}

Movement of the sand particles on the migrating combined-flow ripples was photographed using a still camera and a movie camera under perpendicularly incident lights in the dark room. Neutrally buoyant polystyrene beads $1.5 \mathrm{~mm}$ in diameter were used to trace local flow paths in the water column. Three combinations of oscillatory and unidirectional flows were employed: (1) oscillatory velocity, $U_{o}=17.9 \mathrm{~cm} / \mathrm{s}$, and unidirectional velocity, $U_{u}=16.3 \mathrm{~cm} / \mathrm{s} ;(2) U_{o}=13.0$ $\mathrm{cm} / \mathrm{s}, \mathrm{U}_{\mathrm{u}}=16.1 \mathrm{~cm} / \mathrm{s}$; and $(3) \mathrm{U}_{\mathrm{o}}=7.7 \mathrm{~cm} / \mathrm{sec}, \mathrm{U}_{\mathrm{u}}=19.2 \mathrm{~cm} / \mathrm{sec}$ (YOKOKAWA et al., 1995).

\subsection{Results and Discussions for the Experiments}

\subsubsection{Experimental conditions and formation of combined-flow ripples}

Figure 3 shows the results plotted on a graph of $U_{o}$ vs. $U_{u}$. The $U_{o}-U_{u}$ plot in Fig.3 is partitioned into fields for three bed phases, in the range of flows studied $\left(\mathrm{U}_{\mathrm{o}}: 0-30.6 \mathrm{~cm} / \mathrm{sec} ; \mathrm{U}_{\mathrm{u}}: 0-44.4 \mathrm{~cm} / \mathrm{sec}\right)$. These bed phases were: no movement; wave-dominated combined-flow ripples; and current-dominated combined-flow ripples. The transitions among all these bed phases were gradual. Each of the bed phases in Fig.3 is briefly described in the following subsections.

No movement. The difference in direction of the currents against the waves resulted in different boundaries between the field of no movement and that of wave-dominated combined-flow ripples. In the case of "adverse" unidirectional flow, the upper boundary of the no-movement field sloped downward to the right from a purely oscillatory velocity of about $16 \mathrm{~cm} / \mathrm{sec}$ to a point of about $\mathrm{U}_{\mathrm{u}}=19$ $\mathrm{cm} / \mathrm{sec}$ and $U_{o}=6 \mathrm{~cm} / \mathrm{sec}$. On the other hand, in the case of "favorable" unidirectional flow the upper boundary of the no-movement field may coincide with the vertical line of $U_{o}=16 \mathrm{~cm} / \mathrm{sec}$ in the range of $U_{u}$ from 0 to $19 \mathrm{~cm} / \mathrm{sec}$.

Wave-dominated combined-flow ripples. Throughout the range of $\mathrm{U}_{\mathrm{u}}$ of less than about $19 \mathrm{~cm} / \mathrm{sec}$, except for the range of $U_{o}$ less than $16 \mathrm{~cm} / \mathrm{sec}$, the bed configuration consisted of ripples with straight and laterally continuous sharp crests. Their profiles were very close to that of wave ripples. When $U_{0}$ was high near $30 \mathrm{~cm} / \mathrm{sec}$, the plan views of the ripples became irregular. The values of RRI (ripple roundness index) were less than 0.54, as will be discussed later. As $\mathrm{U}_{\mathrm{u}}$ increased, ripple asymmetry became larger.

Current-dominated combined-flow ripples. When $\mathrm{U}_{\mathrm{u}}$ increased beyond about 19 $\mathrm{cm} / \mathrm{sec}$, ripples with round crests appeared. When the range of $U_{o}$ was less than $16 \mathrm{~cm} / \mathrm{sec}$, this field encroached into the field of wave-dominated combined-flow ripples under "adverse" unidirectional flow. The boundary approximately coincided with the line of $\mathrm{U}_{\mathrm{u}}=\mathrm{U}_{\mathrm{o}}$. Ripples, which appeared in this encroached field, showed almost perfectly symmetry and stronger roundness. In general, the 

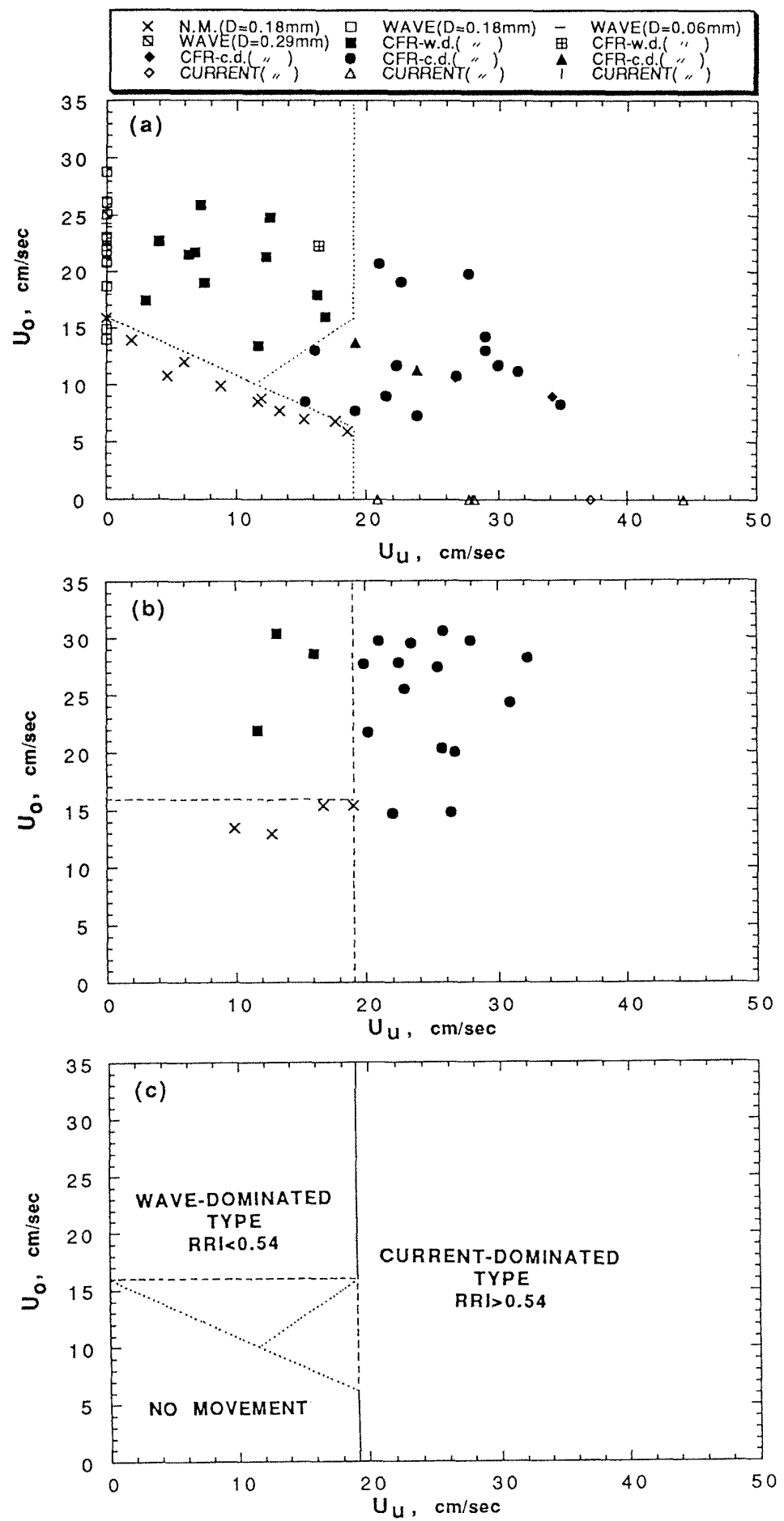

Fig. 3. Experimental results of ripple types under (a) "adverse" currents; and (b) "favorable" currents, plotted on a $U_{o}-U_{u}$ diagram, where $U_{o}$ is oscillatory velocity and $U_{u}$ is unidirectional velocity. (c) A bed phase graph based on the results of (a) and (b). In legend, N.M.: No movements, CFR-w.d.: wave-dominated combined-flow ripples, CFR-c.d.: currentdominated combined-flow ripples, WAVE: wave ripples, CURRENT: current ripples. D in brackets is mean diameter of the sediments. 
crests of current-dominated combined-flow ripples were laterally continuous and slightly sinuous in the width of the flume. The entire streamwise profiles of them looked round because both of the stoss and lee sides were convex-upward. The values of RRI were greater than 0.54 , as will be discussed later. With increasing $\mathrm{U}_{\mathrm{u}}$, ripples became significantly asymmetrical when seen in streamwise profile. The boundary between the wave-dominated combined-flow ripples and currentdominated combined-flow ripples $\left(\mathrm{U}_{\mathrm{u}}\right.$ is about $19 \mathrm{~cm} / \mathrm{sec}$ ) was roughly coincidental with the threshold velocity in the purely unidirectional flow (e.g., HARMS et al., 1982).

\subsubsection{Profiles of combined-flow ripples and their relationship to flow velocities}

General. The main series of experiments was carried out with fine $(0.18 \mathrm{~mm})$ sand. The profiles changed in accordance with changes in flow velocity (Fig.4). When flow was purely oscillatory, the bed showed the profile typical of wave ripples; i.e., symmetrical, concave-upward slopes (Fig.4(a)). When the unidirectional flow velocity was less than $19 \mathrm{~cm} / \mathrm{sec}$, wave-dominated combinedflow ripples developed. The bed profile was very similar to the profiles of wave ripples generated by purely oscillatory flow (Fig.4(b)), except that slightly convex-upward slopes were shown sometimes. Once the unidirectional flow velocity exceeded $19 \mathrm{~cm} / \mathrm{sec}$, current-dominated combined-flow ripples developed. The most characteristic feature of this profile was that both the lee and stoss sides were convex-upward and that the overall shape was rounded (Fig.4(c)). The trough showed concave-upward rounded shape that looked like part of a circular arc. As $U_{u}$ increased, the bed-profile asymmetry became stronger, though its crest was still rounded (Fig.4(d)). The bed profiles were distinct from those of both wave ripples and current ripples. Under purely unidirectional flow, current ripples occur showing strongly asymmetrical, and with straight foreset surfaces (Fig.4(e)).

Effects of unidirectional-flow direction. The essential characteristics of each wave-dominated and current-dominated combined-flow ripple were unaffected by the direction of currents. Successive changes in ripple profile were observed for "favorable" unidirectional flow, in the same way as was described above on "adverse" unidirectional flow (Fig.5). Ripple asymmetry under the "favorable" unidirectional flow was seen to be stronger than that of "adverse" unidirectional flow in a majority of cases.

Effects of grain sizes. Although different grain sizes yielded different ripple sizes (length and height), ripple profiles were very similar. Wave lengths of the combined-flow ripples and current ripples in medium sand was much larger (ca. 2.5 times larger) than that in fine sand. Wave lengths of combined-flow ripples in coarse silt was about $90 \%$ of that in fine sand. The medium sand bed took about three times as longer to build ripples than finer materials.

Ripple index (RI). Ripple index (RI) was calculated for each ripple. The RI values of wave ripples under purely oscillatory flows distributes between 5.4 and 6.8 , and it's median value is 5.96 . For combined-flow ripples under "adverse" 


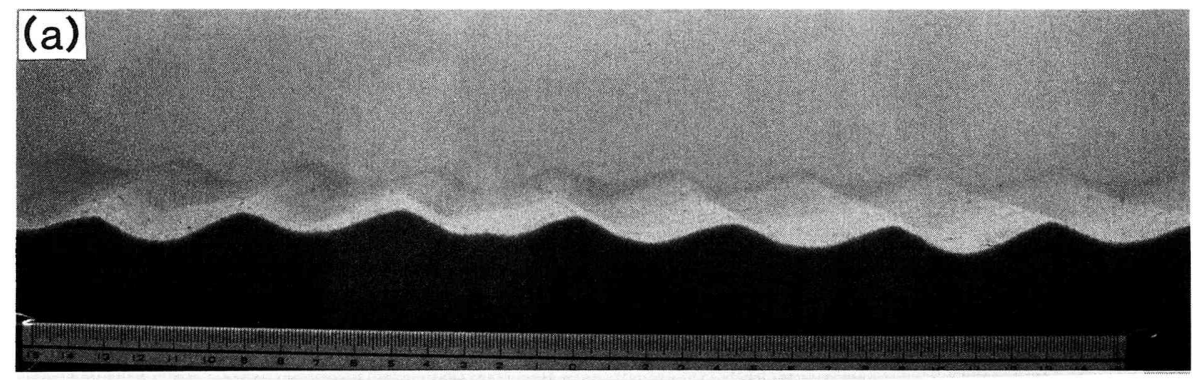

(b)

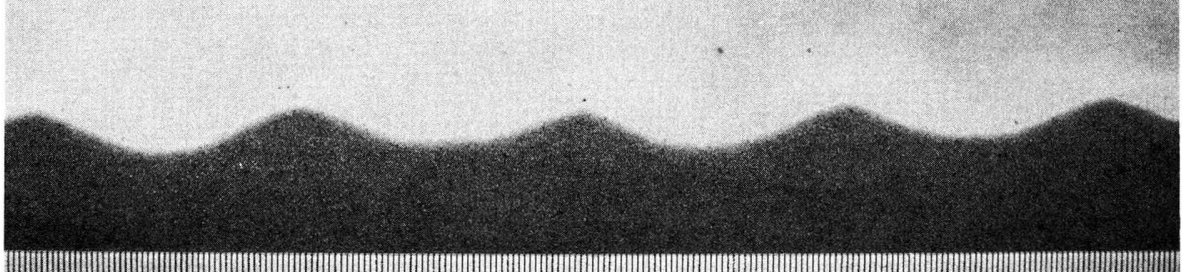
${ }_{3}$

(c)
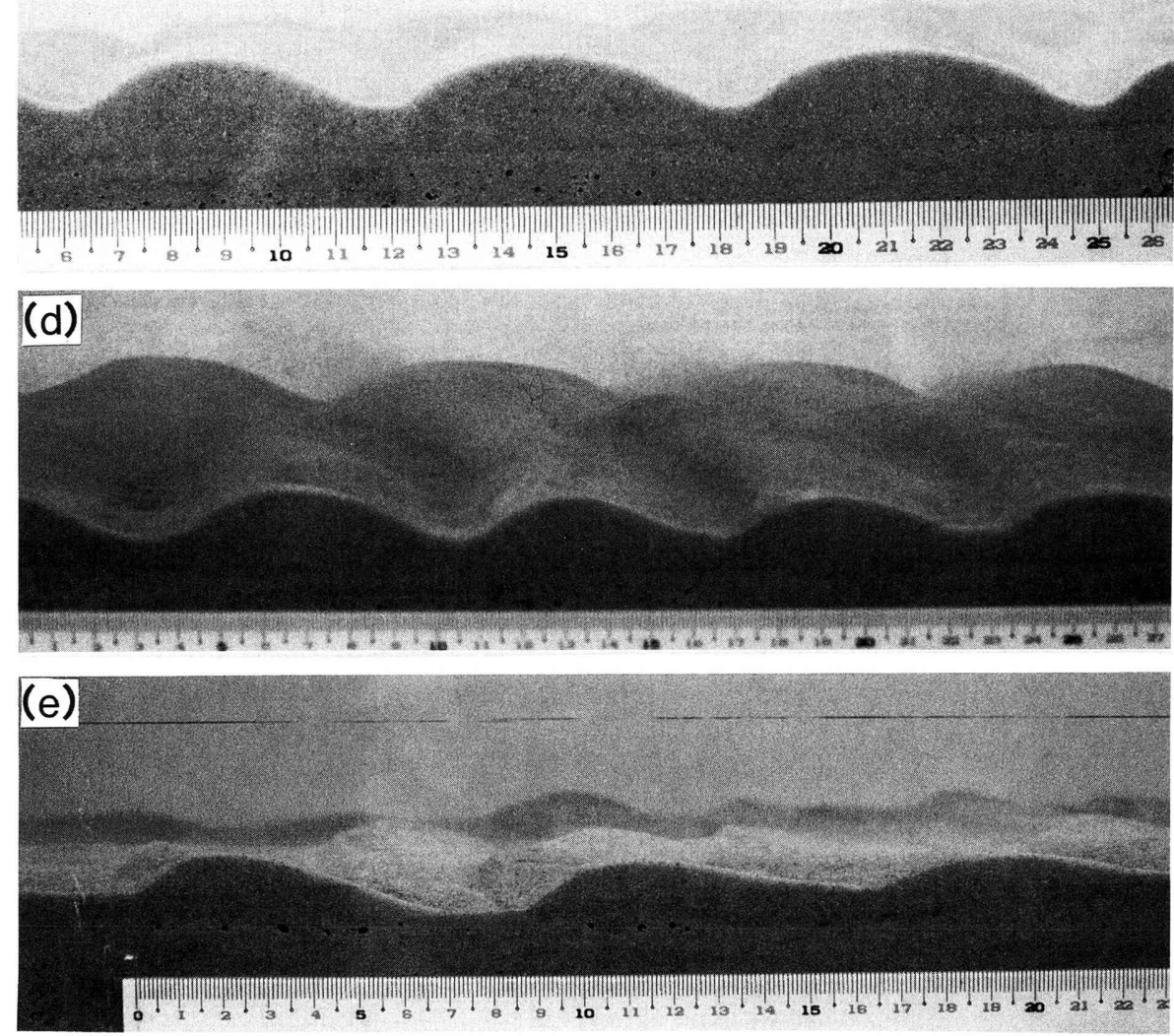

Fig. 4. Ripples formed in fine sand $(\mathrm{D}=0.18 \mathrm{~mm})$. Waves come from the left and currents from the right. Scales are in $\mathrm{cm}$. (a) $U_{\mathrm{o}}=26.1 \mathrm{~cm} / \mathrm{s}$, (b) $U_{\mathrm{o}}=19.0 \mathrm{~cm} / \mathrm{s}$ and $U_{\mathrm{u}}=7.45 \mathrm{~cm} / \mathrm{s}$, (c) $U_{\mathrm{o}}=7.7$ $\mathrm{cm} / \mathrm{s}$ and $U_{\mathrm{u}}=19.2 \mathrm{~cm} / \mathrm{s},(d) U_{\mathrm{o}}=8.3 \mathrm{~cm} / \mathrm{s}$ and $U_{\mathrm{u}}=23.7 \mathrm{~cm} / \mathrm{s}$, and $(\mathrm{e}) \mathrm{U}_{\mathrm{u}}=28.2 \mathrm{~cm} / \mathrm{s}$. 

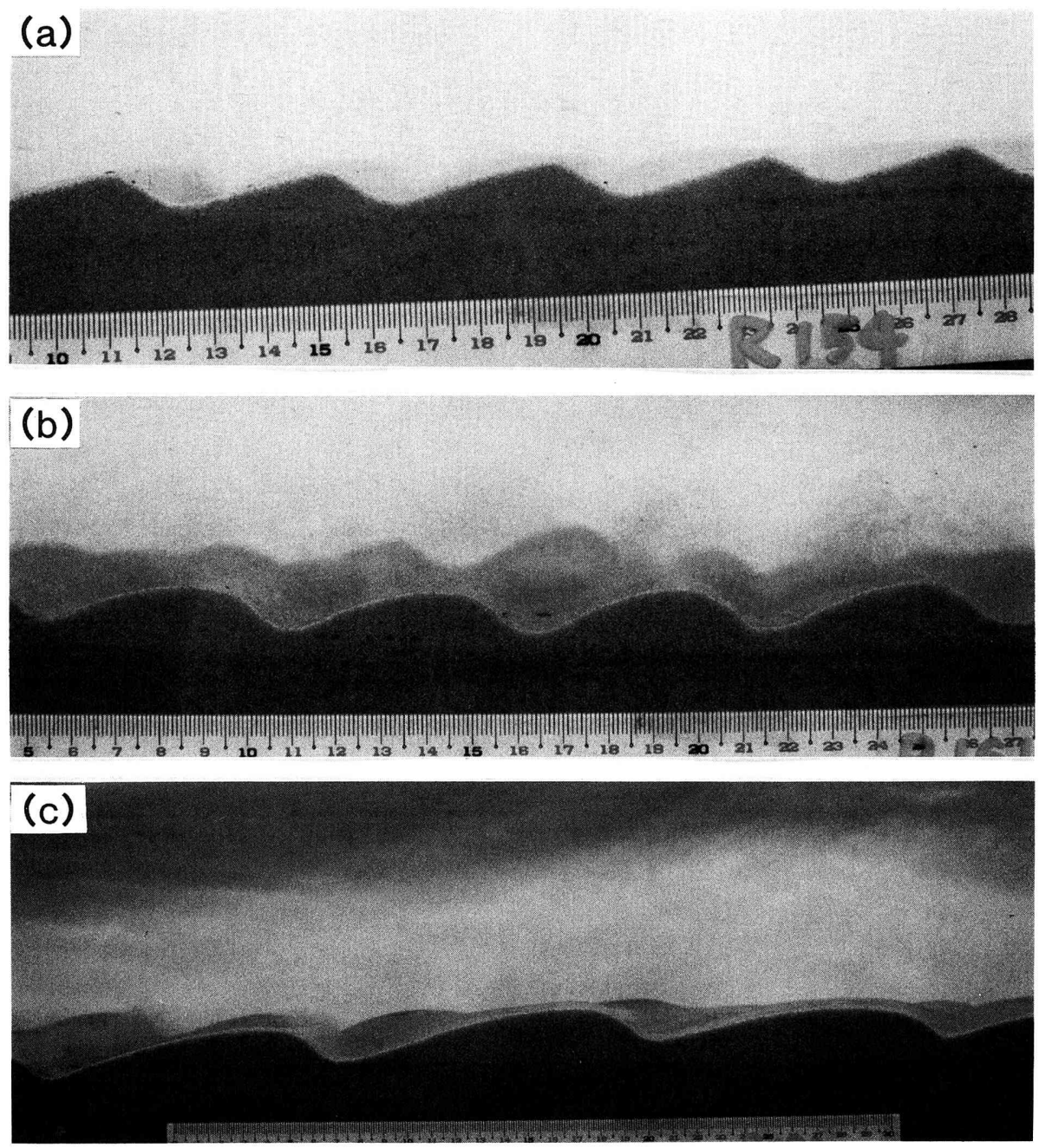

Fig. 5. Combined-flow ripples generated by waves with "favorable" currents (from the left to the right). Scales are in $\mathrm{cm}$. (a) $\mathrm{U}_{\mathrm{o}}=21.9 \mathrm{~cm} / \mathrm{s}$ and $\mathrm{U}_{\mathrm{u}}=11.7 \mathrm{~cm} / \mathrm{s}$, (b) $\mathrm{U}_{\mathrm{o}}=21.7 \mathrm{~cm} / \mathrm{s}$ and $\mathrm{U}_{\mathrm{u}}=20.2 \mathrm{~cm} / \mathrm{s}$, and $(\mathrm{c}) \mathrm{U}_{\mathrm{o}}=20.0 \mathrm{~cm} / \mathrm{s}$ and $\mathrm{U}_{\mathrm{u}}=26.7 \mathrm{~cm} / \mathrm{s}$.

unidirectional flows, RI distributes from 5.2 to 6.8 , and it's median is 6.17. For combined-flow ripples under "favorable" unidirectional flows, from 4.9 to 7.9, median is 6.30. For current ripples under purely unidirectional flows, from 6.0 to 11.1 , and median is 9.47. Only the current ripples can be distinguished on the basis of comparison of their RI values; wave ripples and combined-flow ripples cannot be distinguished in this way. This result is not consistent with HARMS' (1969) observation in that combined-flow ripples were recognizable to a certain extent, because their RI values were greater than 25 .

Ripple symmetry index (RSI) and ripple roundness index (RRI). Ripple symmetry index (RSI) and ripple roundness index (RRI) for each ripple were 


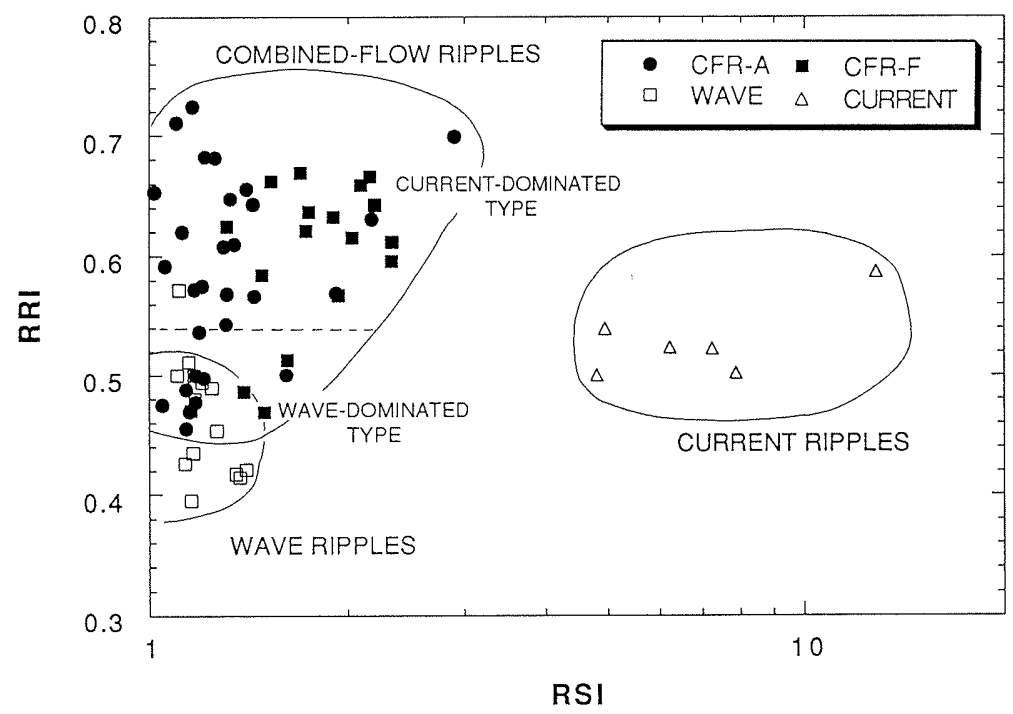

Fig. 6. Ripple profiles presented by two indices: ripple symmetry index (RSI); and ripple roundness index (RRI). Each point shows the median value of the indices for plural ripples generated in a single run. Note that current ripples are clearly distinguishable by the RSI. Combined-flow ripples have higher RRI values, and wave ripples have lower values, although there is a transition zone. In legend, CFR-A: combined-flow ripples generated by oscillatory flow with "adverse" unidirectional flow, CFR-F: with "favorable" unidirectional flow, WAVE: wave ripples, and CURRENT: current ripples.

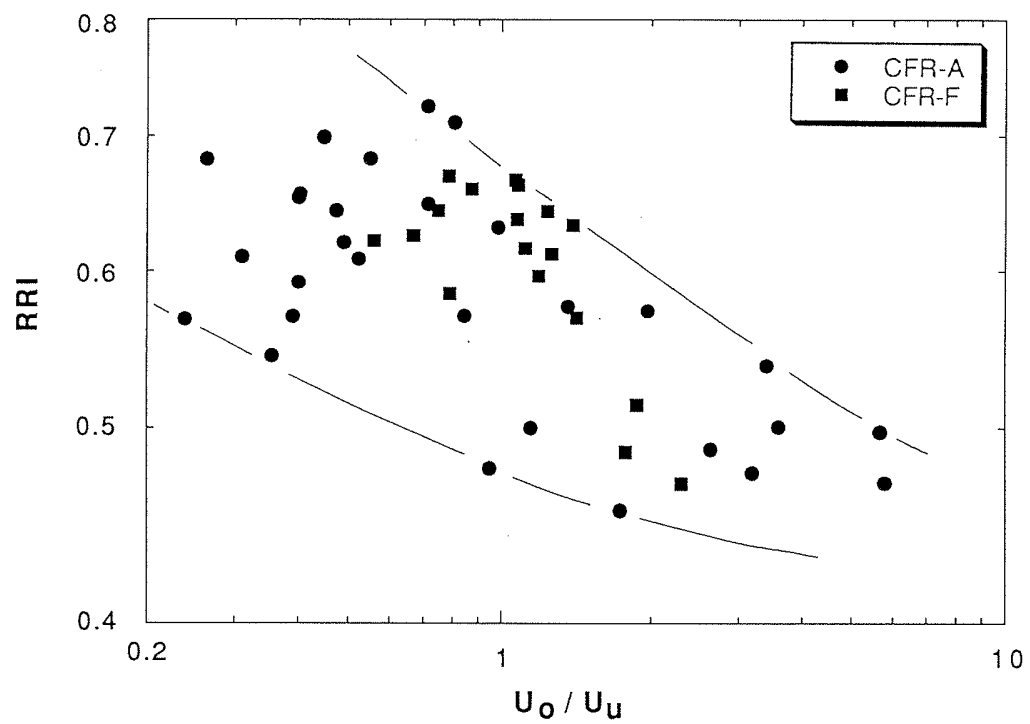

Fig. 7. Relationship between RRI and ratio of oscillatory velocity to unidirectional velocity $\left(\mathrm{U}_{\mathrm{o}} / \mathrm{U}_{\mathrm{u}}\right)$. Note that lower relative oscillatory velocity result in rounder profiles. In legend, CFR-A: combined-flow ripples generated by oscillatory flow with "adverse" unidirectional flow, CFR-F: with "favorable" unidirectional flow. 
calculated. Median values of RSI and RRI for ripples formed on each run have been plotted on a graph of RRI vs. RSI (Fig.6). Ripples generated by purely unidirectional flow (current ripples) are distinguishable from other ripples by means of their high RSI values, i.e., strong asymmetry. The RSI values of current ripples exceeded 4. Although no sharp boundary exists between combined-flow ripples and wave ripples in either the RSI or RRI indices, combined-flow ripples, especially those that are current-dominated, are recognizable in terms of their high RRI values, i.e., round shapes. RRI=0.54 may be the boundary of currentdominated and wave-dominated combined-flow ripples (including wave ripples). The RRI values of wave ripples are less than 0.52 (in all cases but one) and apparent shapes of combined-flow ripples change clearly at this boundary. Ripples which have RRI values less than 0.45 can be considered wave ripples under purely oscillatory flow.

The plot of RRI vs. ratio of oscillatory velocity to unidirectional velocity $\left(\mathrm{U}_{\mathrm{o}} / \mathrm{U}_{\mathrm{u}}\right)$ in Fig.7 shows a slope downward to the right. This means that for combined-flow ripples, RRI values increase (i.e., ripples become more rounded) as relative strength of oscillatory component decreases.

\subsubsection{Internal sedimentary structures of combined-flow ripples}

The internal sedimentary structure of combined-flow ripples was primarily concordant with outer form. Form-discordant structure was built when experimental condition changed in the middle of a single run. Outer forms responded sensitively to changes of flow conditions. On the contrary, internal structure could not change promptly because migration speed of combined-flow ripples was slow. Although the migration speed was faster than that of wave ripples but much less than that of current ripples. The following is the description of form-concordant internal structures which resulted from ripples in equilibrium state in a single run.

The internal sedimentary structures consisted mainly of foreset laminae, dipping in the same direction along which ripples moved. No remarkable distinguishing factor between the internal sedimentary structures of "adverse" and "favorable" unidirectional flows could be observed. The internal structures of current-dominated and wave-dominated combined-flow ripples differed, keeping the differences in their outer forms. The characteristics of each structure are described in the following subsections.

Current-dominated combined-flow ripples. Lamination within ripples always dipped in the direction which steeply inclined lee sides faced. Ripples always moved in the downcurrent of the unidirectional component, under currentdominated combined-flow $\left(\mathrm{U}_{\mathrm{u}}\right.$ is greater than $19 \mathrm{~cm} / \mathrm{sec}$ ).

The convex-upward round shape of the combined-flow ripples resulted in convex-upward round, sigmoidal foreset laminae (Fig.8(b)). This was the most remarkable characteristic of the internal structure of combined-flow ripples. The angle of a foreset lamina changed twice in a single foreset: at the brink point and the toe point. The part above the brink point showed a convex-upward curve, although the angle of dip was much less than that seen under the brink point (10 15 degrees). The steepest angle, ca. 32 degrees (ranges from 25 to 40 degrees), 


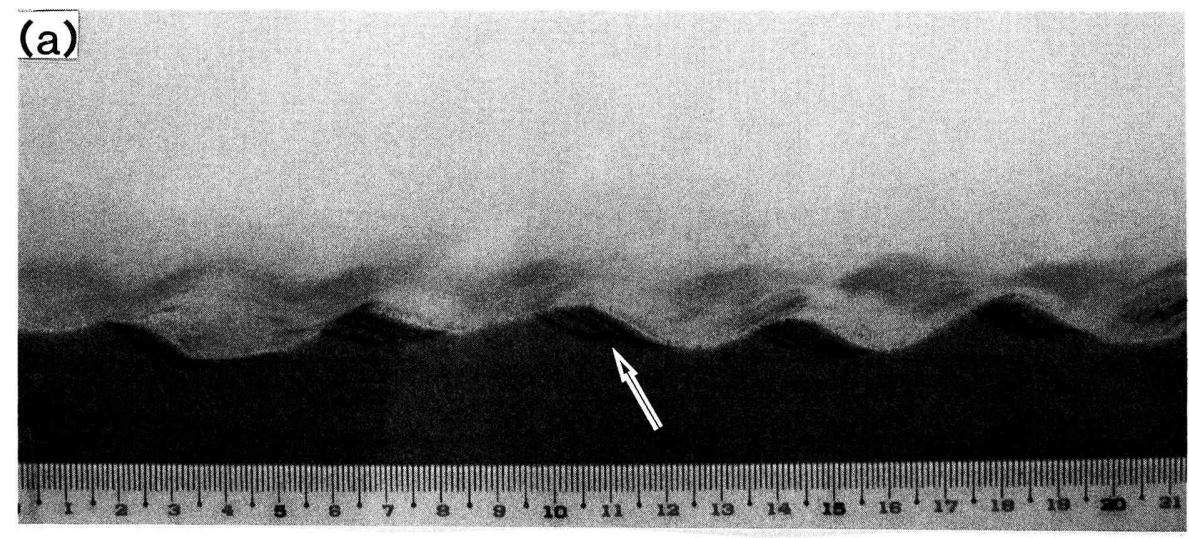

\section{(b)}

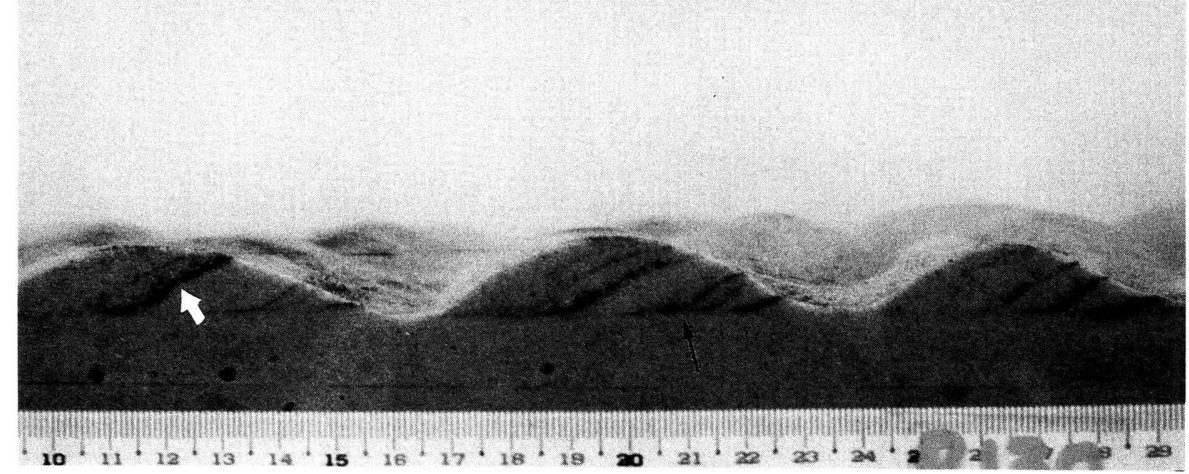

Fig. 8. Internal sedimentary structures of combined-flow ripples generated by oscillatory flow with "adverse" unidirectional flow. Oscillatory flow comes from the left and unidirectional flow from the right. (a) Wave-dominated combined-flow ripples. An arrow shows truncated troughs. $\left(\mathrm{U}_{\mathrm{o}}=17.4 \mathrm{~cm} / \mathrm{s}\right.$ and $\mathrm{U}_{\mathrm{u}}=3.0 \mathrm{~cm} / \mathrm{s}$ ). (b) Current-dominated combined-flow ripples. A "joined" structure which looks small protuberance (an open arrow) and truncated troughs (a solid arrow) are observed $\left(\mathrm{U}_{\mathrm{o}}=14.2 \mathrm{~cm} / \mathrm{s}\right.$ and $\left.\mathrm{U}_{\mathrm{u}}=29.0 \mathrm{~cm} / \mathrm{s}\right)$. Scales in $\mathrm{cm}$.

was observed between the brink and toe points. In that zone, the foreset laminae also showed a convex-upward curve. A thick part of the lamina above and near the toe point was conspicuous (see Figs.9(b) and (c), a solid thick arrow). Sometimes that part appeared as a small protuberance (see Figs.9(c), thin solid arrow, and 8(b), open arrow). This structure, named as "joined" structure, is a very characteristic feature of combined-flow ripples (Figs.8(b), 9 and 10(b)), and can be used as one of the criteria. The peculiar movement of sand grains under combined-flows yields this characteristic structure; i.e., a vortex generated on a trough erodes and lifts sand, and some part of the sand is deposited above the toe point and makes a small protuberance (Fig.9(a), an arrow). Then an avalanche of sand comes down and covers the foreset, so that the thick "joined" part or the protuberance appears (Figs.9(b) and (c)). Sand particle movement on migrating ripples have been discussed by YOKOKAWA et al.(1995) (see 2.2.5 in detail).

In the part lower than the toe point, the lamina was concave-upward and had a low angle (10 - 15 degrees) tangential to the lower bounding surface. This part 

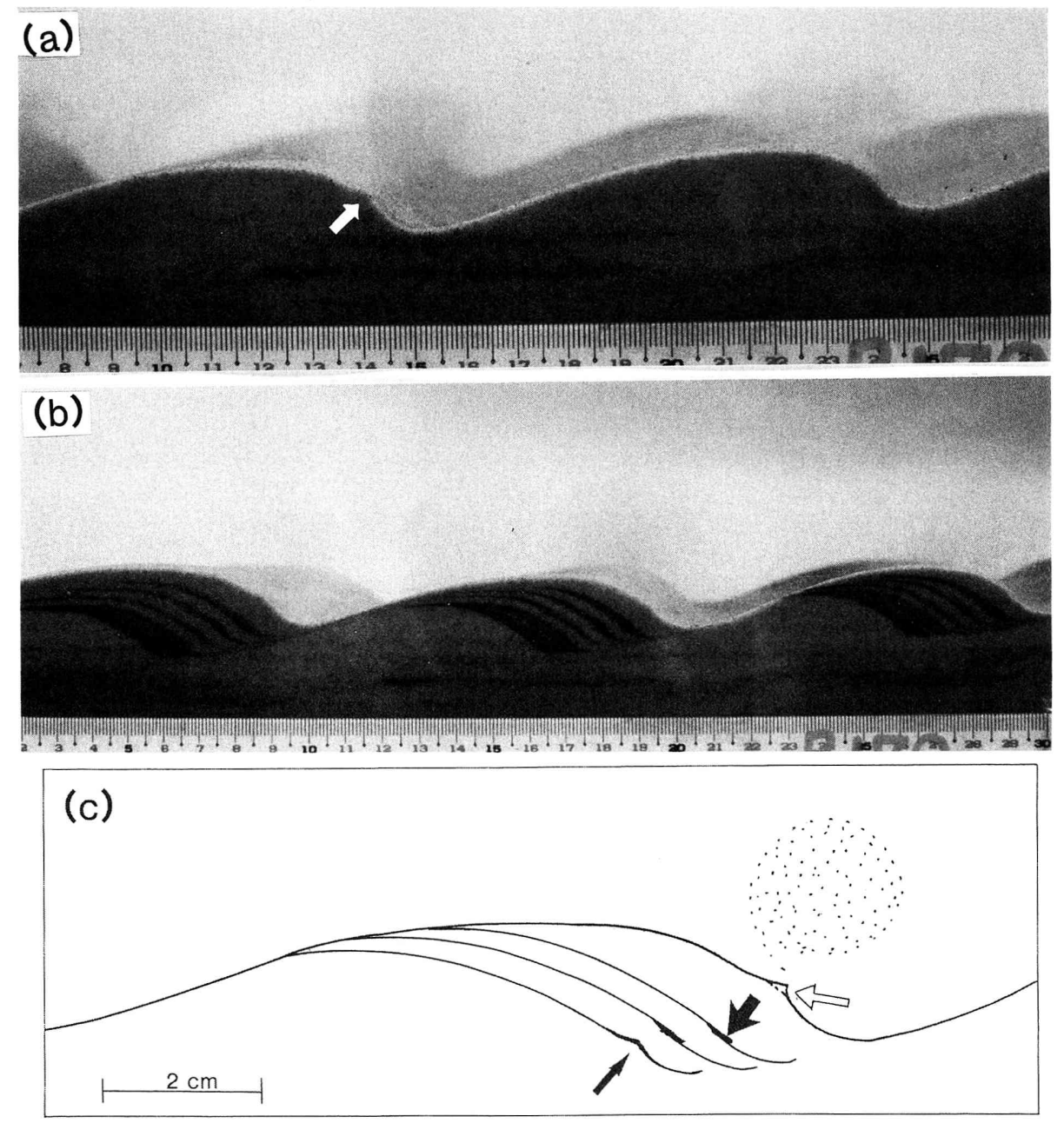

Fig. 9. A formative process of the "joined" structure. (a) A protuberance (arrow) yielded by deposition from suspended sand. This part is continuously covered by avalanching sand, and results in the "joined" structure (b) of combined-flow ripples. Combined oscillatory flow $\left(\mathrm{U}_{\mathrm{o}}=27.8 \mathrm{~cm} / \mathrm{s}\right)$ with "favorable" unidirectional flow $\left(\mathrm{U}_{\mathrm{u}}=22.5 \mathrm{~cm} / \mathrm{s}\right)$ came from the left to the right. Scales in $\mathrm{cm}$. (c) Schematic drawing of the "joined" structures (thin and thick solid arrows). An open arrow shows the protuberance on the foreset.

seemed to be on the production of the trough. The shape of the trough looked approximately like a circular arc. The lamination yielded as a result of the migration of the circular arc-like trough showed truncation of the former lamination (e.g., Fig.8(b), solid arrow). This structure will be called "truncated trough" in later. When new sediment was added while ripples migrated the circular arc-like shape is preserved well (Fig.10(b)).

When no new sediment was added while ripples migrated, only the lower part of the foreset laminae was preserved. However even that is enough to distinguish wave or current ripple laminations by the following characteristics: the extremely sigmoidal shape of the toe; the "joined" structure; and the truncated trough.

Wave-dominated combined-flow ripples. The lamination dipped in the same 

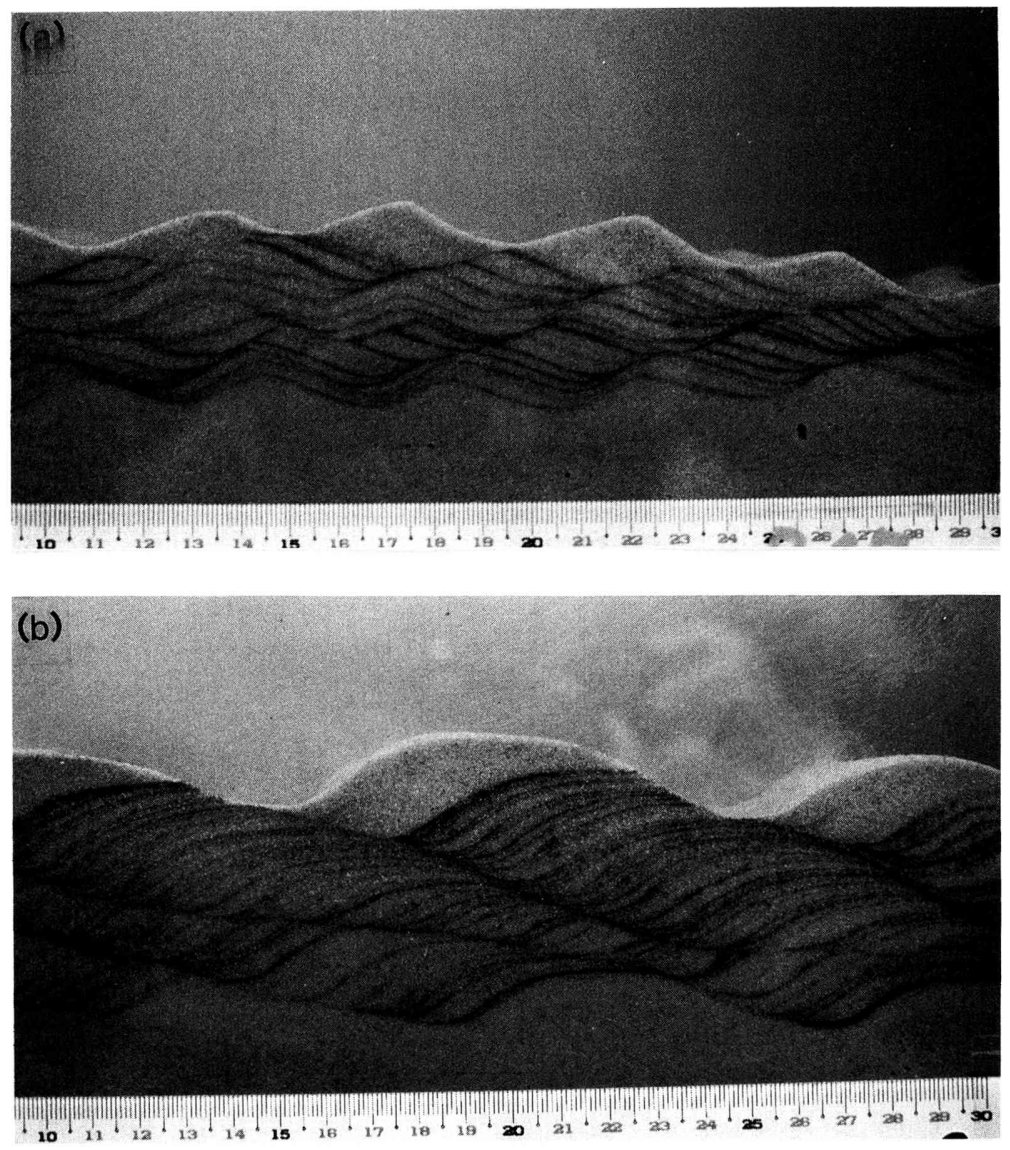

Fig. 10. Climbing ripple laminations generated by oscillatory flow with "adverse" unidirectional flow. Oscillatory flow comes from the left and unidirectional flow from the right. (a) Wavedominated combined-flow ripples $\left(U_{\mathrm{o}}=25.9 \mathrm{~cm} / \mathrm{s}\right.$ and $\left.U_{\mathrm{u}}=7.2 \mathrm{~cm} / \mathrm{s}\right)$. (b) Current-dominated combined-flow ripples $\left(U_{o}=13.0 \mathrm{~cm} / \mathrm{s}\right.$ and $\left.U_{u}=29.0 \mathrm{~cm} / \mathrm{s}\right)$. Scales in $\mathrm{cm}$.

direction in which ripples moved, although the direction did not always coincide with the downcurrent direction of a unidirectional component. The angle of foreset lamina did not vary much in a single foreset without toe part, so that the foreset lamina looked more or less like a straight line, although it was sometimes convex-upward (Figs.8(a) and 10(a)). The angle of these dips was about 20 degrees (ranges from 17 to 26 degrees). The toesets were tangential or concave to lower bounding surfaces. The bottomset showed truncation of the former lamination (Fig.8(a), arrow). That can be an index of existence of the combined-flow, since wave ripples do not show that kind of structure, but instead, usually offshooting lamination which sweeps up and ascends on the adjacent ripple body under formation.

\subsubsection{Grain fabric of combined-flow ripples}

Current-dominated combined-flow ripples. In the middle and lower parts of the foreset lamina, imbrication of apparent long axes of sand grains was dominated by 

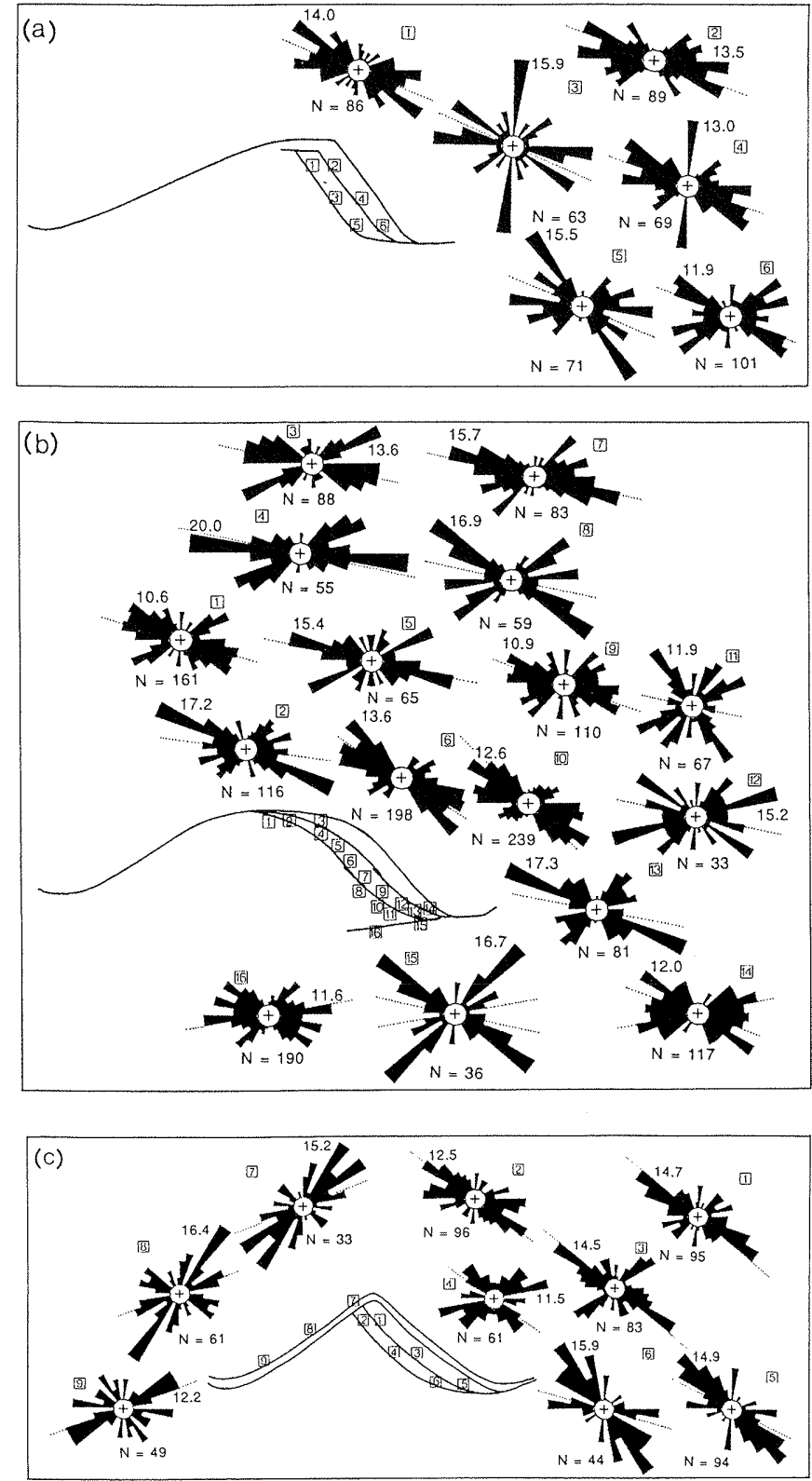

Fig. 11. Rose diagrams for sand grain fabrics of (a) current ripples, (b) current-dominated combined-

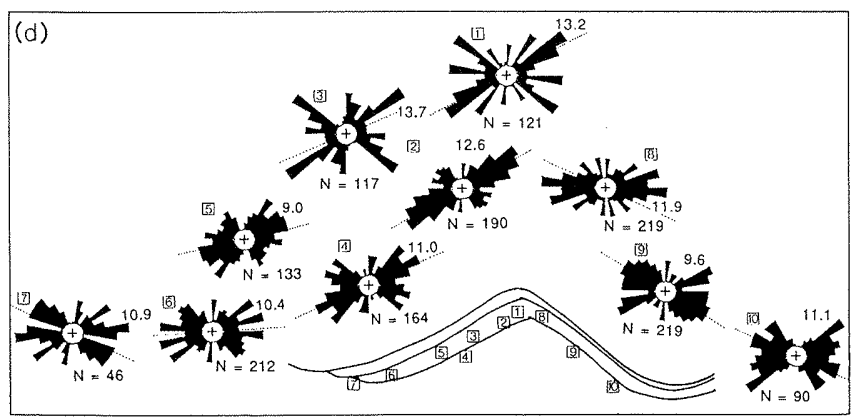
flow ripples, (c)wave ripples and (d) wave-dominated combined-flow ripples. For each diagram, $\mathrm{N}$ means number of counted grains, the number besides the diagram denotes the maximum percentage of distribution of long axes, and the dashed line shows the dipping angle of the lamina. 


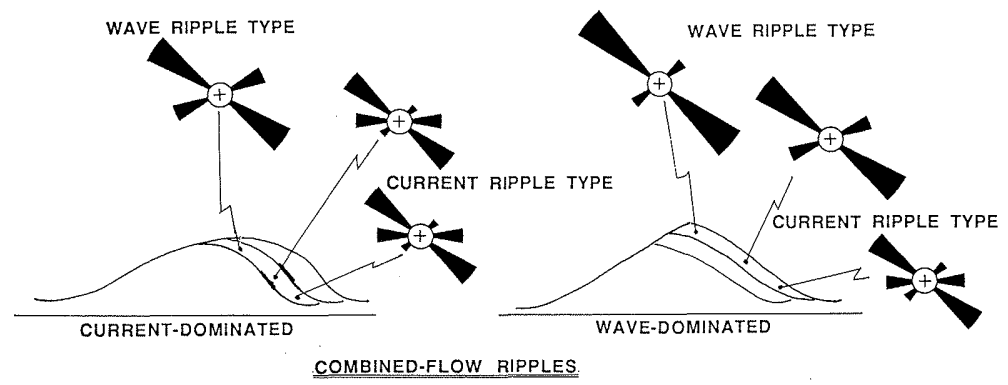

Fig. 12. A schematic model for sand grain fabric of combined-flow ripples.

the angles that intersected with the lamina at low angles $(0-20$ degrees), with high angles (50 - 70 degrees), and parallel to the horizontal line (Figs.11(b) and 12). These characteristics are shared by the grain fabric of current ripples (Fig.11(a)). Standard deviations were larger than those of wave ripples. On the other hand, the grain fabric of the upper part of the foreset lamina showed two peaks: the first was along the laminae, and the second was an angle of symmetry with respect to a perpendicular (Figs.11(b) and 12). This fabric was similar to wave-affected fabrics (Fig.11(c); YOKOKAWA and MASUDA, 1990), although their secondary peaks were much smaller.

Wave-dominated combined-flow ripples. The upper and middle parts of foreset lamina were dominated mainly by the grains imbricated along the lamina. The second peaks appeared at relatively high angles (30 - 70 degrees) to the lamina. This second peak was more remarkable in the middle part of the foreset lamina (Figs.11(d) and 12). This fabric is similar to that of wave ripples (Fig.11(c)). The standard deviations showed low values as compared with current-affected grain fabrics. In the lower part of the foreset lamina, grains settled parallel to the horizontal line and dipped in an upcurrent direction with a high angle to the lamina dominant beside the grains along the lamina (Figs.11(d) and 12). The fabric of this part is similar to that of current ripples rather than wave ripples.

Grain fabrics of combined-flow ripples were characterized by coexistence of preferred imbrication patterns of both wave and current ripples in a single foreset lamina as discussed above. A schematic model for the grain fabrics of combined-flow ripples was proposed in Fig.12. The upper parts were similar to wave ripples whose grain fabric is considered to be formed by grains lifting once and then falling to the site. On the other hand, the lower parts were dominated by fabric similar to the current ripples whose grain fabric should be built by an avalanche of grains. Detailed arrangements of the fabrics differed between the current-dominated combined-flow ripples and wave-dominated combined-flow ripples.

\subsubsection{Sand particle movement on migrating combined-flow ripples}

The observation of the sand particle movements revealed that the movement of sand particles on the migrating combined-flow ripples differed from those on both current and wave ripples (YOKOKAWA et al., 1995; Figs.13 and 14). The 


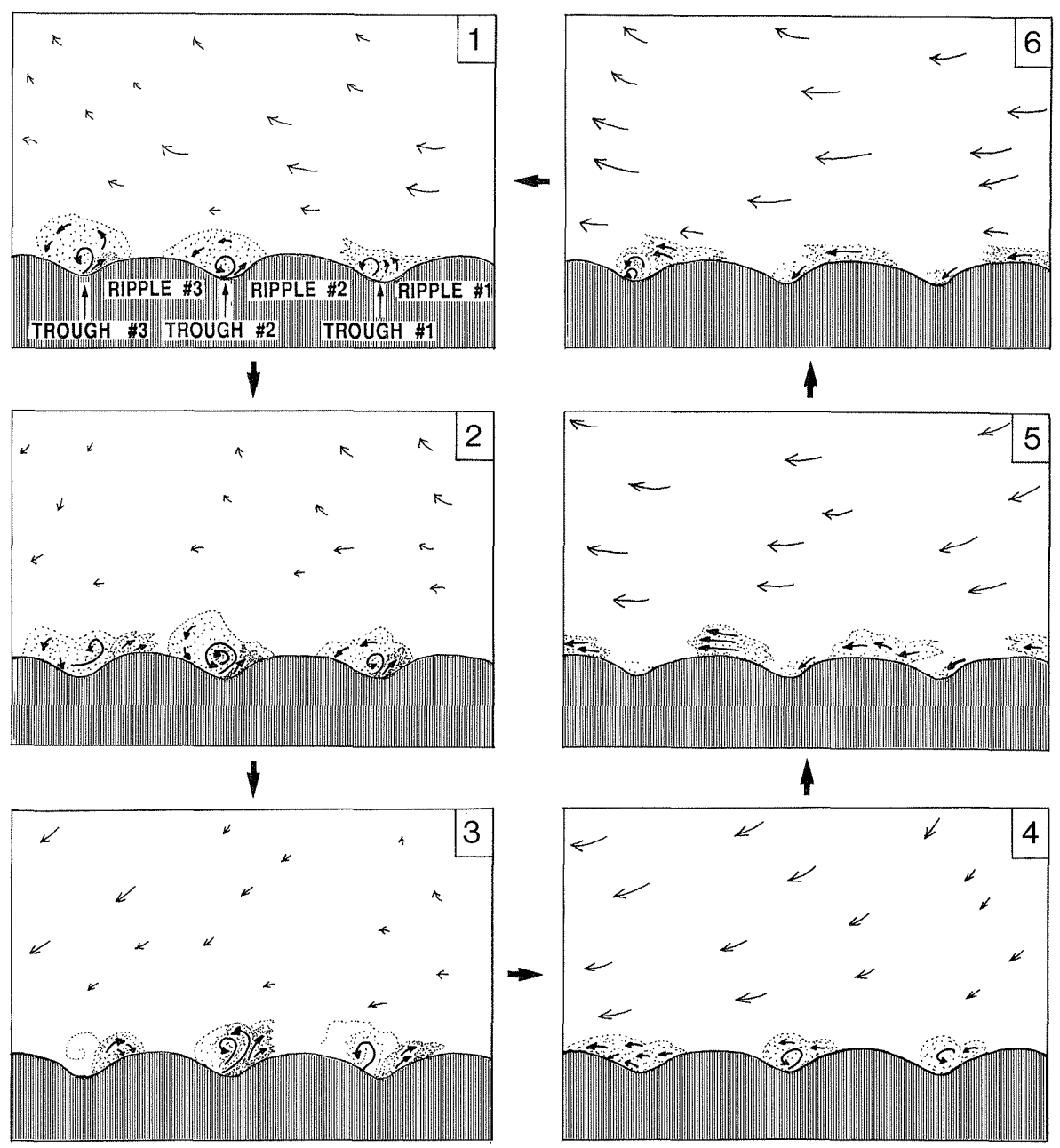

Fig. 13. Schematic view of sand transport during one near-bed oscillation. Oscillatory flow comes from the left and unidirectional flow from the right. The length of the arrow shows the relative magnitude of the flow velocity.

roundness of combined-flow ripples results from characteristic movements both of water and sand particles under combined-flow.

According to YOKOKAWA et al. (1995), the flow lines go down with periodic, small, ascending loops. The diameter of these loops becomes bigger as the orbital velocity becomes higher. The vortices, generated only close to the lee sides of ripples, are responsible for the rounded profile. These vortices dig troughs in circular arcs, and lift sand particles. They are then pulled upward along the lee sides with sand particles to deposit on the midway and upper parts of the lee sides. The lee sides are fertilized by sand, contributing a convex-upward profile. The flow that separates at the crest is dragged into the vortices at the troughs, so that there is no clear reattachment point with focused erosion. Sand that falls to the bed from a floating cloud over the stoss side nourishes the convex-upward rounded stoss side. The difference of direction of unidirectional flow yields no 


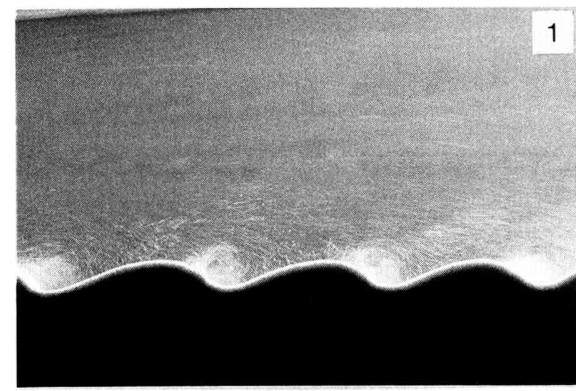

$\downarrow$

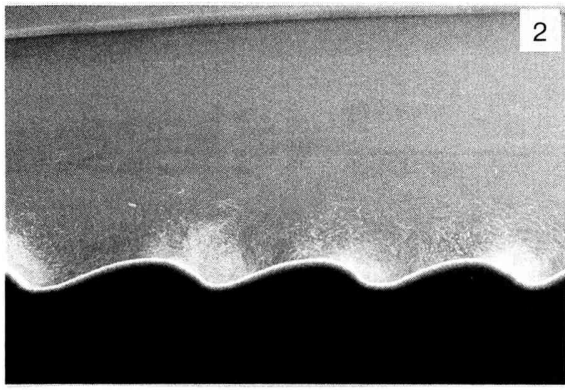

$\downarrow$

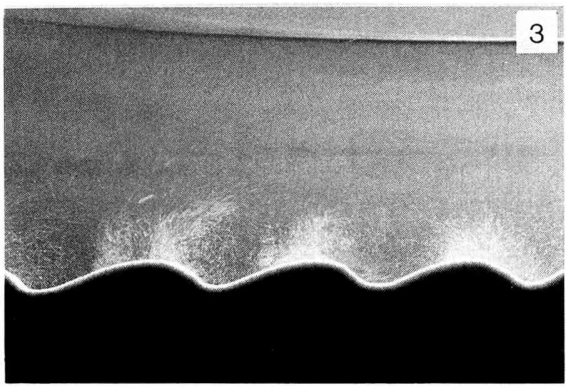

Fig. 14. Six phases of sand movement on migrating combined-flow ripples during one near-bed oscillation. Both oscillatory and unidirectional flows come from the left. The vertical length of each photograph is ca. $20 \mathrm{~cm}$.

essential difference of movement (Fig. 14).

Offshore migration is mainly attributed to accretion of sand lifted by vortices on the lee sides, unlike the way that current ripples migrate by avalanche on the lee sides which look straight as the results. When a purely unidirectional flow generates current ripples, the flow separates at the crest and reattaches at the base of the stoss side of the adjacent downstream ripple, where vigorous erosion produces a flat stoss side. In the case of combined flow, the flow that becomes detached at the crest is dragged into the vortex at the trough, so that the free stream line never reaches the adjacent, downstream stoss surface to cause erosion. Instead, this stoss surface is characterized by deposition from a migrating sand cloud, producing a convex-upward, rounded stoss side. The intervening round troughs are generated by vortices.

The roundness of the combined-flow ripples varies with the places where the vortices burst and where vortices change from upcurrent to downcurrent travel in 
the oscillatory flow field. When the oscillatory-flow velocity is relatively high, the vortex generated at the trough drawn over brink point and sand particles are carried onshore over the crest to the stoss side (YOKOKAWA et al., 1995, Fig.3(a)). The lee side, eroded by the vortex, remains concave upward and the crest is sharp. This process occurs on both sides of the ripple in purely oscillatory flows to form wave ripples with sharp crests. With each stroke of the oscillatory flow, deposited sand makes an ephemeral bulge on the downstroke side of each crest, but the bulge is eroded by the opposite stroke. On the contrary, a lower relative oscillatory flow velocity yields smaller vortices that cause little erosion of the lee side. In addition, the sand suspended by these vortices nourishes the lee sides, making depositional bulges around the brink point. This results in more rounded ripple profiles (YoKOKAWA et al., 1995, Fig. 3(c)).

\section{Applications for Geologic Records}

The experimental results described above were applied to geologic records to prove those criteria available for discrimination of combined-flow ripples from wave and current ripples. The following subchapters show the results of the application and discussions about them.

\subsection{Differentiation of Wave Ripples and Combined-Flow Ripples}

Current-dominated combined-flow ripples in the Pleistocene Kioroshi Formation in Dejima Upland, Ibaraki. The combined-flow ripples in Fig.15 occur in the late Pleistocene Kioroshi Formation of the upper part of the Shimosa Group (OKAZAKI and MASUDA, 1992) exposed in a quarry at Sakihama, Dejima upland, Ibaraki, central Japan. The Kioroshi Formation deposited during the "Shimosueyoshi transgression" (0.11 - $0.13 \mathrm{Ma})$, and successive highstand and regressive periods. In this quarry, the Kioroshi Formation consists of lowermost

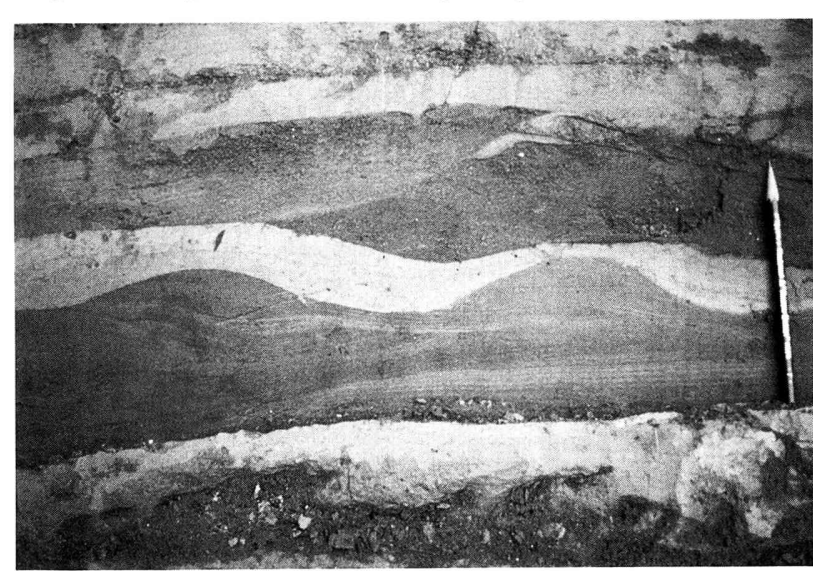

Fig. 15. Current-dominated combined-flow ripples of shoreface storm deposits of the Pleistocene Kioroshi Formation in Sakihama, Dejima Upland, Ibaraki, Japan. Ripples with characteristic rounded profiles are composed of fine to very fine sand and are covered by a clay bed. The pencil (ca. $15 \mathrm{~cm}$ ) as scale. valley-fill burrowed mud layer ( $5 \mathrm{~m}$ thick), a well sorted inner bay sand (3.8 $m$ thick), an alternation of sand and mud layers of inner bay deposits $(2 \mathrm{~m}$ thick) which contain the combined-flow ripples, a hummocky cross-stratified shoreface sand ( $5 \mathrm{~m}$ thick), and parallel-laminated beach sand ( $1 \mathrm{~m}$ thick) in ascending order (MASUDA and MAKINO, 1987, columnar section no.5 of Fig.2). The alternation possesses a basal part which comprises coarse sand, including shell fragments, and is 
interpreted as a transgressive lag. The core of the alternation consists of storm sand sheets less than a few decades $\mathrm{cm}$ and mud layers less than $20 \mathrm{~cm}$ which was deposited from suspension of flooding.

The ripples developed in the uppermost parts of the storm sand sheets, and are composed of fine to very fine sand. This sand was originally deposited as a hummocky bed as suggested by the internal structure. In this case, the extremely rounded profiles indicate existence of current-dominated combined flows that reworked the hummocky bed in the ripple regime. Respective wave lengths of the combined-flow ripples are $22.4 \mathrm{~cm}$ and $23.4 \mathrm{~cm}$, and the wave heights are $3.6 \mathrm{~cm}$ and $2.8 \mathrm{~cm}$. RSI values are 1.5 and 1.1 , and RRI are 0.79 and 0.63 . These values fall into the field of current-dominated combined-flow ripples (Fig.6). These ripples have been interpreted as wave ripples in previous works (KATSURA et al., 1985; MAKINO and MASUdA, 1986a; MASUdA and MAKINO, 1987; OKAZAKI and MASUDA, 1989). In fact, some storm sand sheets among these are topped by "wave" ripples generated by purely oscillatory flow. They have sharp crests with concave-upward slopes and chèron upbuilding or offshooting structures, and almost all are composed of coarse silt, including pellets, although the underlying HCS comprises fine to very fine sand. These facts suggest that weaker oscillatory flows, which can rework only coarse silt sized particles formed the ripples after the combined-flow waned.

Current-dominated combined-flow ripples in the Cretaceous Kimigahama Formation in Choshi Peninsula, Chiba. The combined-flow ripples in Fig.16 occur in the Lower Cretaceous Kimigahama Formation of the lower part of the Choshi Group, in Kimigahama, Choshi Peninsula, Chiba, central Japan. The Kimigahama Formation (ca. $90 \mathrm{~m}$ in thickness) consists of an alternation of medium- to finegrained sandstone and bioturbated mudstone, which shows a thinning- and finingupward, deepening-upward sequence (KATSURA et al., 1984, Fig.1). Sandstone

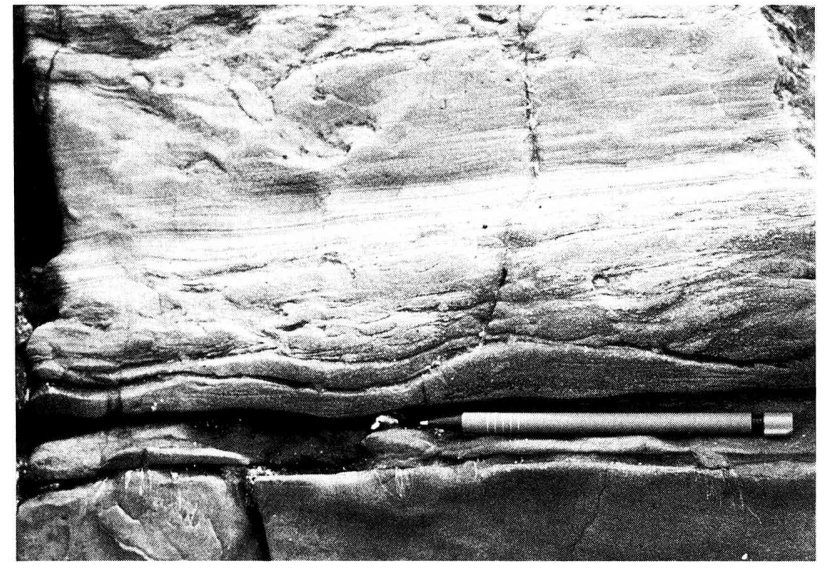

Fig. 16. Current-dominated combined-flow ripples in shoreface deposits of the Cretaceous Choshi Group in Inubo-zaki, Choshi, Chiba, Japan. Sandstone beds with rounded ripples and bioturbated thin mud beds are intercalated in HCS sandstones. The pencil (ca. $14 \mathrm{~cm}$ ) gives scale. beds thicker than $10 \mathrm{~cm}$, (although sandstone bed exceeding $1 \mathrm{~m}$ are rare,) contain hummocky crossstratifications or parallellaminations covered with ripple cross-lamination. The depositional environment of the formation is interpreted as shoreface to shelf (KATSURA et al., 1984).

Ripples in the sand layers often show asymmetric, rounded profiles (as in Fig.16), indicating that they were generated under current-dominated combined flows. The rip- 
ples are composed of very fine-grained sand. The wave lengths of the ripples are $10.1 \mathrm{~cm}$ and $16.6 \mathrm{~cm}$, and the wave heights are $0.8 \mathrm{~cm}$ and $1.8 \mathrm{~cm}$. RSI values are 1.75 and 1.78 , and RRI values are 0.57 and 0.56 . These values fall into the field of current-dominated combined-flow ripples (Fig.6).

Wave-dominated combined-flow ripples in the Plio-Pleistocene Upper Osaka Group in Neyagawa, Osaka. The combined-flow ripples in Fig.17 occur in the Middle Pleistocene, the Upper Osaka Group ("Marine clay 7 - 8") exposed in a quarry at Neya, Neyagawa, Osaka, southwest Japan. In the studied outcrop, a single transgressive and regressive cycle between the "Marine clay 7" and the "Marine clay 8" are observed (SAKAMOTO et al., 1991). The depositional age for these horizons can be estimated about 0.5 - 0.6 Ma after MASUDA (1993). It comprises the following five units in ascending order: the lowermost mud layer and alternation of sand and mud layers which are deposits of tidal-channel fills, interchannels and lagoons (3.6 m thick); alternation of sand and mud layers, containing current ripples and mud drapes, interpreted as sand-flat deposits $(2.5$ $\mathrm{m}$ thick); wave and combined-flow rippled or hummocky cross-stratified sand intercalated with mud layers interpreted as shoreface deposits (3 m thick);
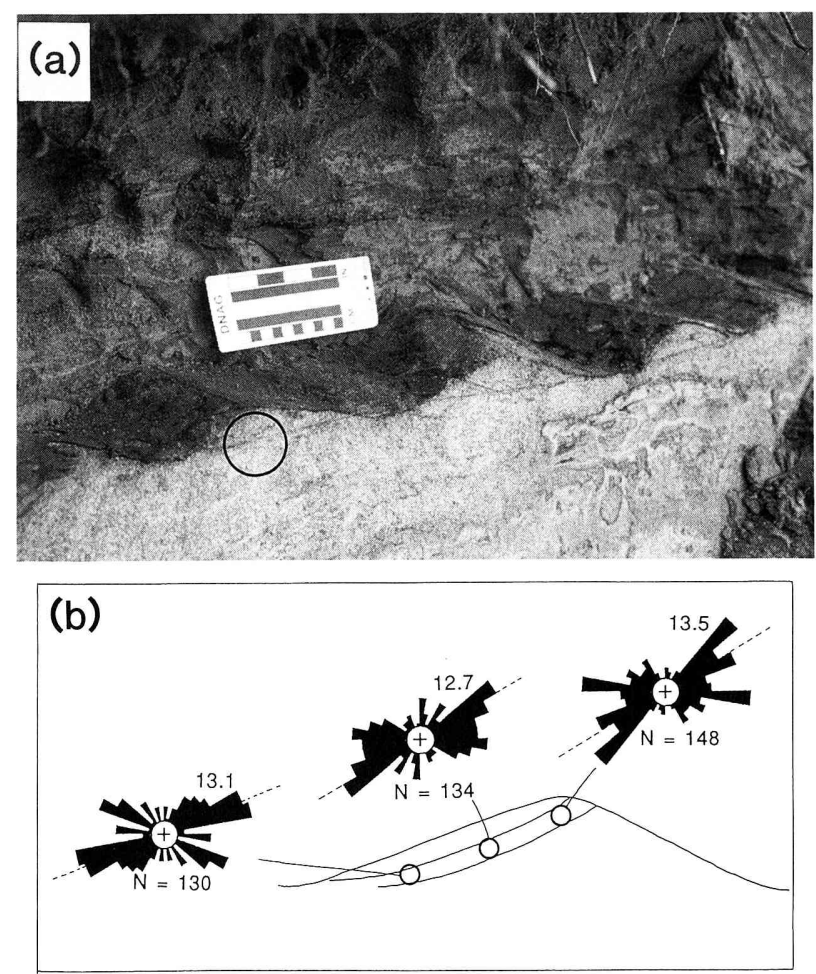

Fig. 17. (a) Wave-dominated combined-flow ripples in upper shoreface deposits of the Pleistocene Osaka Group, Neyagawa, Osaka, Japan. Ripples with slightly convexupward foresets are composed of medium sand. (b) Rose diagrams of sand grain fabric of the foreset (encircled in (a)) show the character of that of wave-dominated combined-flow ripples. For legend, see Fig.11. parallel laminated granular sand of beach deposits $(2.4$ $\mathrm{m}$ thick); and trough and tabular cross-stratified granular sand with an erosional base of fluvial channel deposits $(2.7 \mathrm{~m}$ thick) (SАKАмото et al., 1991, Fig.7).

The ripples (Fig.17(a)) developed in the lowermost $1 \mathrm{~m}$ of the upper shoreface deposit. These ripples are not associated with hummocky beds. They are composed of medium sand, and covered with mud layers a few $\mathrm{cm}$ thick. The ripple crests are almost parallel, although they sometimes bifurcate. The wave lengths of the ripple range between $18 \mathrm{~cm}$ and $35 \mathrm{~cm}$, the wave heights $3.0 \mathrm{~cm}$ and $4.4 \mathrm{~cm}$. The ripples are almost symmetrical and have slightly convex-upward slopes. Their RSI values range 
from 1.00 to to 0.58 . They can, therefore, be recognized as wave-dominated combined-flow ripples, although some ripples show RRI values of currentdominated combined-flow ripples, not wave ripples (Fig.6). The grain fabric of the foreset part shows the characteristic fabric of wave-dominated combined-flow ripples as follows (Fig.17(b)): The fabric in the upper and middle parts shows almost the same distribution pattern being dominated by grains which is parallel to the laminae and dipping upslope of $30-40$ degrees against the laminae. The fabric in the lower part has a different pattern from that in other parts, showing three peaks such as being parallel to the lamina, dipping upslope of $40-60$ degrees against the lamina and parallel to the horizontal line.

\subsection{Combined-Flow Ripples in Tidal Deposits}

Modern examples of combined-flow ripples in tidal flats. Fig.18 shows example of combined-flow ripples in modern tidal flats, observed in the back-barrier beach of Spiekeroog Barrier Island, southern North Sea, Germany. The tidal range at the Spiekeroog is up to $2.8 \mathrm{~m}$ (FLEMMING and DAVIS, 1992). The ripples are composed of fine sand and show a characteristic rounded profile with almost perfect symmetry. These ripples are interpreted as having been formed by tidal currents and waves which are generated by wind traveling across the back-barrier area. The wave lengths of the ripples are $8.7 \mathrm{~cm}, 9.3 \mathrm{~cm}$ and $9.5 \mathrm{~cm}$, wave heights are $1.4 \mathrm{~cm}, 1.5 \mathrm{~cm}$ and $1.3 \mathrm{~cm}$. RSI values are $1.19,1.23$ and 1.27 , and RRI values are $0.66,0.59$ and 0.61 . These ripples can be identified as current-dominated

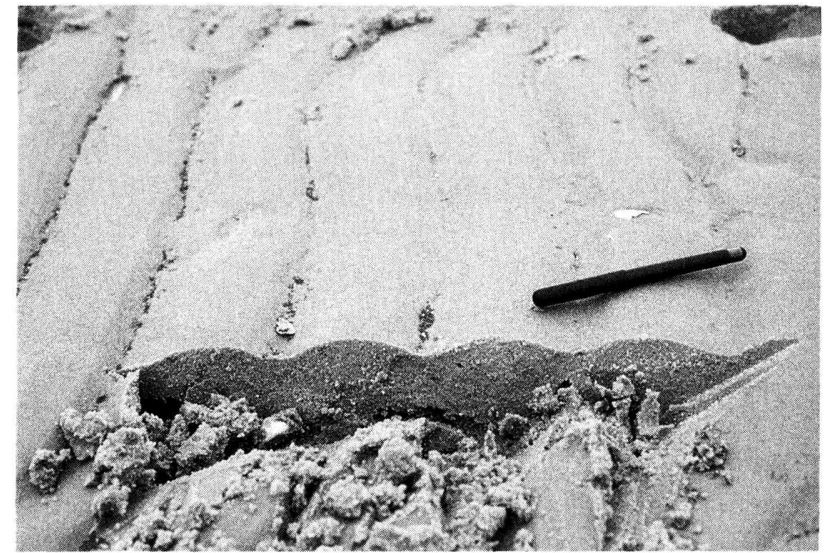

Fig. 18. Current-dominated combined-flow ripples, showing rounded and symmetric profiles, in modern intertidal back-barrier beach of Spiekeroog Barrier Island, southern North Sea, Germany. Seaward is to the left. A ball-point pen $($ ca. $14 \mathrm{~cm}$ ) gives scale. 1.32, and the RRI values from 0.50 combined-flow ripples (Fig. 6).

The Pleistocene Tahara Formation in Atsumi Peninsula, Aichi. The ripples in Fig. 19 occur in the middle Pleistocene Tahara Formation, in the middle part of the Atsumi Group (HIROKI and KIMIYA, 1990) in a quarry of Tahara, Atsumi Peninsula, Aichi, central Japan. The Tahara Formation is interpreted as a deposit during a single transgressive - regressive cycle and overlain by the

Toyohashi Formation, whose age is estimated about $0.3 \mathrm{Ma}$ by correlation of volcanic ash layers. The ripples are contained in the lower part of the Tahara Formation. This part consists of tidal deposits included in the upper part of a drowned-valley deposit (about $4.6 \mathrm{~m}$ thick) that forms the base of the formation with an erosional base overlying a beach deposit (about $3 \mathrm{~m}$ thick) in the uppermost part of Futagawa Formation. The drowned-valley deposit is overlain 
by a fan delta (or spit) deposit consisting of pebbles (about $6 \mathrm{~m}$ thick). This pebble layer underlies the lower shoreface deposit which mainly consists of hummocky cross-stratified sands (10 m thick) (HIROKI and KIMIYA, 1990, Fig.7, columnar section no.25).

The ripples occur just beneath the tabular cross-laminated fine to medium sand. The thickness of the cross lamination changes systematically, suggesting

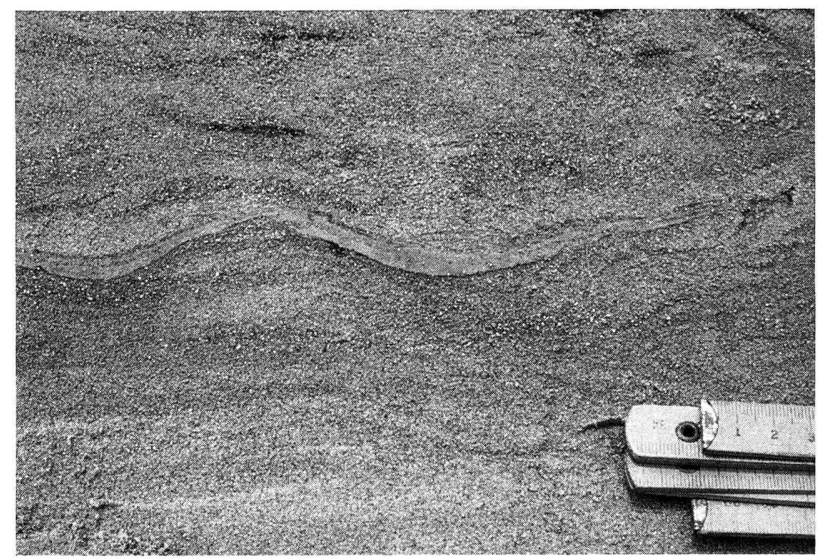

Fig. 19. Combined-flow ripple of tide-influenced deposits of the Pleistocene Atsumi Group, Atsumi Peninsula, Aichi, Japan. The ripple has rounded profile, and is composed of fine sand. The scale is $4.5 \mathrm{~cm}$ long.

combined flows.

The Pleistocene Tanabe Formation in Keihanna Hill, Kyoto. The ripples in Fig.20 occur in the early Pleistocene Zakuro Alternation Member of the Tanabe

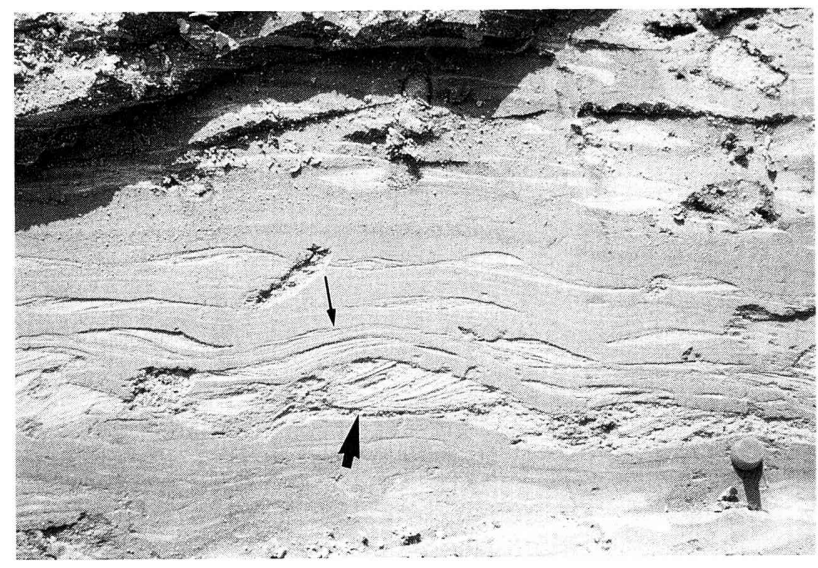

Fig. 20. Combined-flow ripples in sub-tidal deposits of the Pleistocene Osaka Group in Seika-machi, Keihanna Hill, Kyoto, Japan. Ripples composed of very fine sand occur in a parallel laminated clay bed. Notice the rounded profiles, concave-upward foreset laminae (a thin arrow) and truncated trough (a thick arrow). The thumbtack (diameter $=8 \mathrm{~mm})$ as scale. tide-influenced deposition (e.g., NIO and YANG, 1989). The ripples are composed of fine sand, and covered with a thin (up to $5 \mathrm{~mm}$ ) mud layer. It could not be inferred whether these are subtidal or intertidal deposits. The wave length and height of the ripple (Fig.19) is $10 \mathrm{~cm}$ and 1.4 $\mathrm{cm}$, respectively. The RSI value is 1.37 , and the RRI value is 0.56 . The ripple shows a rounded and slightly asymmetric profile, indicating formation under current-dominated

Formation, the lower Osaka Group (MitAmuRA, 1992) in a quarry of Inuidani, Seika-cho, Keihanna Hill, Kyoto, southwest Japan. The Zakuro Alternation Member occupies the upper part of the Tanabe Formation (MitamuRA, 1992), and is composed of sandlayer-dominated alternation of sand and silt layers, which indicates deposition in fluvial to estuarine environments. In the middle part of the Zakuro Alternation Member, a thick (5 - $8 \mathrm{~m})$, grayish blue-colored mud 
layer with trace fossils like Ophiomorpha and plant fragments is interbedded and correlated to the "Marine clay 1" (SomekaWA and YoshikaWA, 1983). The Zakuro Alternation Member appears in the quarry, and is about $50 \mathrm{~m}$ thick. It consists of the following units: silt layers with rootlets and plant fragments interbedded in trough cross-stratified sand layers, which are fluvial flood-plain and channel-fill deposits (about $28 \mathrm{~m}$ thick); a thick mud layer (13 m thick), whose lower part shows drowned-valley fill facies containing plant fragments ("Marine clay 1 "), and whose uppermost part is burrowed and intercalated by thin sand layers, which include the combined-flow ripples, indicating subtidal environments; trough or tabular cross-laminated sand with mud drapes $(1.4 \mathrm{~m}$ thick); and alternation of trough cross-stratified sand and silt layers of fluvial deposits $(5 \mathrm{~m}$ thick).

The ripples in Fig.20 are composed of very fine sand, and appear as lenticular beddings in parallel laminated clay. Foreset laminae of the ripples dip to the opposed directions. The lenticular bedding and bidirectional foresets of ripples indicate deposition in subtidal environments (e.g., REINECK and SINGH, 1980). The wave length of the ripple is $9.2 \mathrm{~cm}$, and the wave height is $1.3 \mathrm{~cm}$. The ripple has an asymmetric rounded profile: RSI value is 1.79 and RRI value is 0.68 , which indicate that the ripple is a current-dominated combined-flow ripple. The internal sedimentary structures show a unidirectional sense of migration, and truncated troughs (thick solid arrow). Convex-upward foreset laminae are partly preserved (thin arrow), also indicating a combined-flow which generated this combined-flow ripple. These structures were yielded by a combination of tidal currents and waves.

\subsection{Coarse-Grained Ripples in Shoreface Deposits}

Coarse-grained ripples are often found in transgressive shoreface deposits. LECKIE (1988) and CHEEL and LECKIE (1992) have studied them in detail. They have suggested that the coarse-grained ripples are distal facies of fine-grained hummocky storm beds, and have concluded about the physical process for the coarse-grained ripples as "asymmetrical oscillatory currents generated by shoaling waves". On the other hand, JENNETTE and PRYOR (1993) described coarse-grained asymmetrical ripples as products of combined flows based on their asymmetric profiles and unidirectional dipping foreset laminae. In this chapter, coarse-grained ripples will be examined using the experimental results of the present study.

The Pleistocene Kioroshi Formation in Namekata Upland, Ibaraki. Coarsegrained ripples (Fig.21) occur in the Pleistocene Kioroshi Formation, in the upper part of the Shimosa Group (MURAKOSHI and MASUdA, 1992), at Wagomi, Namekata Upland, Ibaraki, central Japan. These have been described as "wave dunes" by MAKINO and MASUDA (1986b). The base of the coarse-grained ripples coincides with the base of the Kioroshi Formation, which rests unconformably upon the shoreface deposit of the underlying formation, that has not been well defined, of the Shimosa Group. The coarse-grained ripples overlie the trough cross-stratificated and well-sorted bioturbated fine sand including shells of shoreface deposits (4 m thick) (MAKINO and MASUDA, 1986b ; Fig.2). The coarse- 


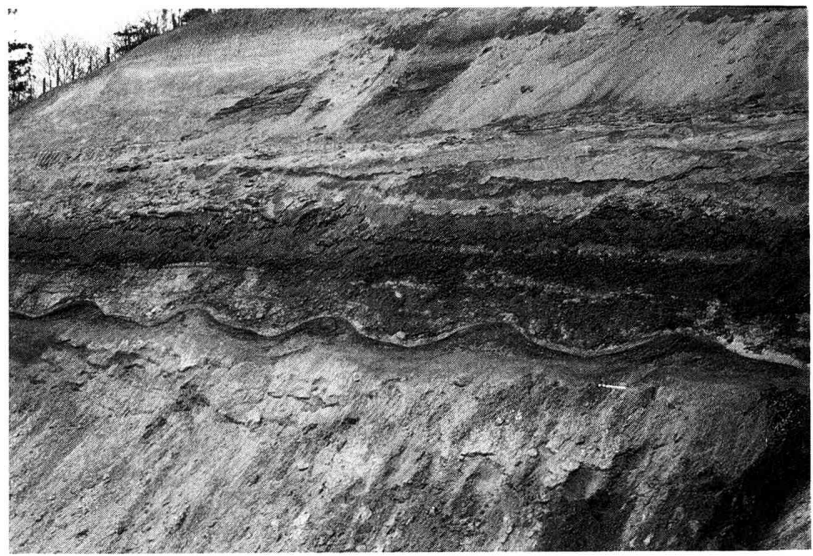

Fig. 21. Coarse-grained ripples in upper shoreface deposits of the Pleistocene Shimosa Group, Wagomi, Namekata Upland, Ibaraki, Japan. Rounded and slightly asymmetric ripples are composed of coarse sand to granule. The sickle (35 cm long) as scale. grained ripples are interpreted as the sequence boundary associated with "Shimosueyoshi transgression" (MURAKOSHI and MASUDA, 1992), and are overlain by a single coarsening-upward and finingupward cycle. The cycle is composed of mud to medium sand which is troughcross laminated and wave ripple cross-laminated and is explained as a bottomset of a flood tidal delta (MURAKOSHI and MASUdA, 1992) (4 m thick). This is overlain by large tabular cross-laminated granular coarse sand of wash-over fan deposit (MURAKOSHI and MASUDA, 1991, 1992) (6 m thick).

The coarse-grained ripples (MAKINO and MASUDA,1986b, Fig.5) are composed of mainly granule to very coarse sand including pebbles, and are capped by a mud layer $90 \mathrm{~cm}$ thick. The wave length of the ripples falls in a range of $100-150 \mathrm{~cm}$, with wave height of about $15 \mathrm{~cm}$. The profiles of the ripples show slightly asymmetric, rounded shape, whose RSI values are $1.0-1.3$, and RRI values are 0.45 - 0.58. The half of RRI values exceeds 0.54 ; indicating current-dominated combined-flow ripples, and the remainder has values from 0.45 to 0.54 ; indicating wave-dominated combined-flow ripples. The internal sedimentary structure of the ripples mainly comprises unidirectional dipping (WNW: onshore direction; MAKINO and MASUDA, 1986b) foreset laminae. Many of them represent the lower parts of the foreset laminae, showing concave-upward shapes. Truncated troughs, one of the criteria of combined-flow ripples, are sometimes preserved among them. The dipping direction of the foreset laminae does not always coincide with the migration direction that is suggested by the ripple profiles. These phenomena were often observed in wave-dominated combined-flow ripples in flume experiments. In this example, the coarse-grained ripples are interpreted as wavedominated combined-flow ripples, although there are some possibility of currentdominated combined-flow ripples. No evidence which strongly suggest that the coarse grained ripples have been formed by purely oscillatory flow were found.

Pleistocene Usagidani Formation in Niitsu Hills, Niigata. Another example of coarse-grained ripples (Fig.22) occurs in the early Pleistocene Usagidani Formation (KISHI et al., 1992), at Yashiroda, Kosuto, Niitsu Hills, Niigata, Japan. The Usagidani Formation consists of deposits of a fan delta, barrier island system and wave-dominated shoreface (shallowing-upward) in ascending order. The coarse-grained ripples are intercalated in the shoreface deposits. They are 


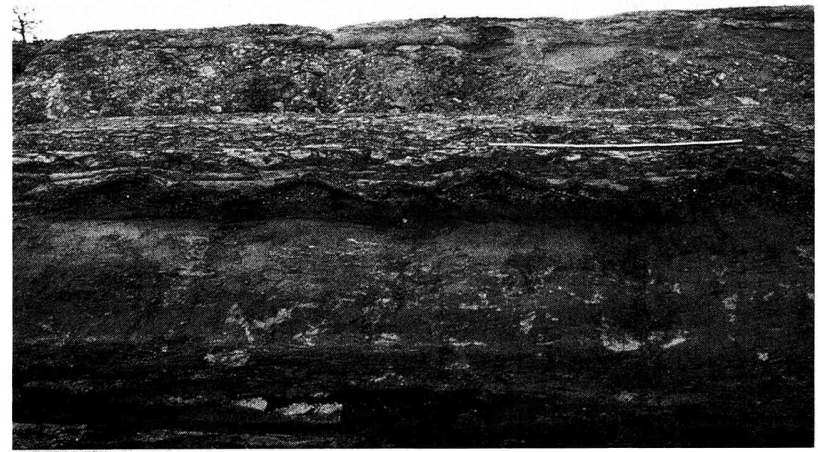

Fig. 22. Coarse-grained ripples in shoreface deposits of the Pleistocene Usagidani Formation, Yashiroda, Niitsu Upland, Niigata, Japan. Symmetric ripples with slightly convex-upward foresets are composed of pebbly very coarse sand. The scale is $1 \mathrm{~m}$ long.

associated with trough, or tabular cross-stratification, wave ripple crosslamination, and hummocky cross-stratification. The coarse-grained ripples are composed of pebble to very coarse sand, covered with an about $1 \mathrm{~cm}$ thick mud layer and represents symmetric profiles. The wave lengths of the ripples range between $65 \mathrm{~cm}$ and $90 \mathrm{~cm}$, and wave heights between $11 \mathrm{~cm}$ and $13 \mathrm{~cm}$. RSI values range between 1.0 to 1.15 , and RRI values between 0.43 to 0.49 . The internal structures are difficult to recognize in many case, but some ripples show concave-upward foreset laminae dipping unidirectionally. The slightly convex-upward slopes of the outer form suggests that these ripples were generated by wave-dominated combinedflow. However, because the RRI values fall into the coexistent field of wave ripples and wave-dominated combined-flow ripples (Fig.6), it is impossible to decide whether the ripples are formed by purely oscillatory flow or wavedominated combined flow in this case.

\subsection{Combined-Flow Ripples within a 'Hummocky Sequence'}

Hummocky cross-stratification (HCS) has been widely known as a representative structure of storm deposits since the description by HARMS et al. (1975). DOTT and BOURGEOIS (1982) were the first to propose an 'ideal sequence' for discrete HCS sandstones, showing structures that are preferentially associated in outcrops within sandstone beds containing HCS. This corresponds to a deposition during a single storm. The sequence consists of a sharp base eroding the underlying mudstone, a hummocky cross-stratified part, a parallellaminated part, a ripple cross-laminated part, and finally overlying mudstone. The ripples, which locate sequentially above hummocky beds or flat beds, have been pointed out as combined-flow ripples (e.g., DOTT and BOURGEOIS, 1982; NøTTVEDT and KREISA, 1987; LECKIE and KRYSTINIC, 1989), based on the description of HARMS (1969), which concentrates on the outer forms of the ripples. LECKIE and KRYSTINIC's (1989) basis for the combined-flow is mainly on offshore unidirectional dipping of internal structures.

The physical process which leads to the formation of HCS is still a matter of controversy. Recent studies, however, of the genetic experiments of HCS (SOUTHARD et al., 1990; ARNOTT and SOUTHARD, 1990) and grain fabric analysis of HCS (YoKOKAWA and MASUDA, 1991; CHEEL, 1991) have revealed that, although symmetric HCS can be formed by purely oscillatory flow, the 'hummocky 
sequence' can be explained better through combined unidirectional flow and oscillatory flow (e.g., CHEEL, 1991; DuKe et al., 1991; CHEEL and LECKIE, 1993). In the interpretation for 'hummocky sequence' by CHEEL (1991) and DUKE et al. (1991), combined flow diminished before the deposition of hummock part. The recognition of the combined-flow ripples in the 'hummocky sequence' may provide good clues regarding the process of HCS formation. The existence of combinedflow ripples above the hummock part shows another possibility of the interpretation; i.e., combined flow lasts its influence through the deposition of 'hummock sequence'.

Some examples of recognition of combined-flow ripples within a 'hummocky sequence' through the application of experimental results obtained in the present study are introduced below. One of the examples was already described in the Chapter 3.1. (Pleistocene Kioroshi Formation in Ibaraki; Fig.15).

Miocene Shirahama Formation in Kii Peninsula. The discrete HCS sandstone in Fig.23 occurs in the lower Miocene Shirahama Formation, Tanabe Group in a quarry of Tanosaki, Uchinoura, Tanabe, Wakayama, Kii Peninsula, southwest Japan. The Shirahama Formation (600 - $700 \mathrm{~m}$ thick) is divided into five members:

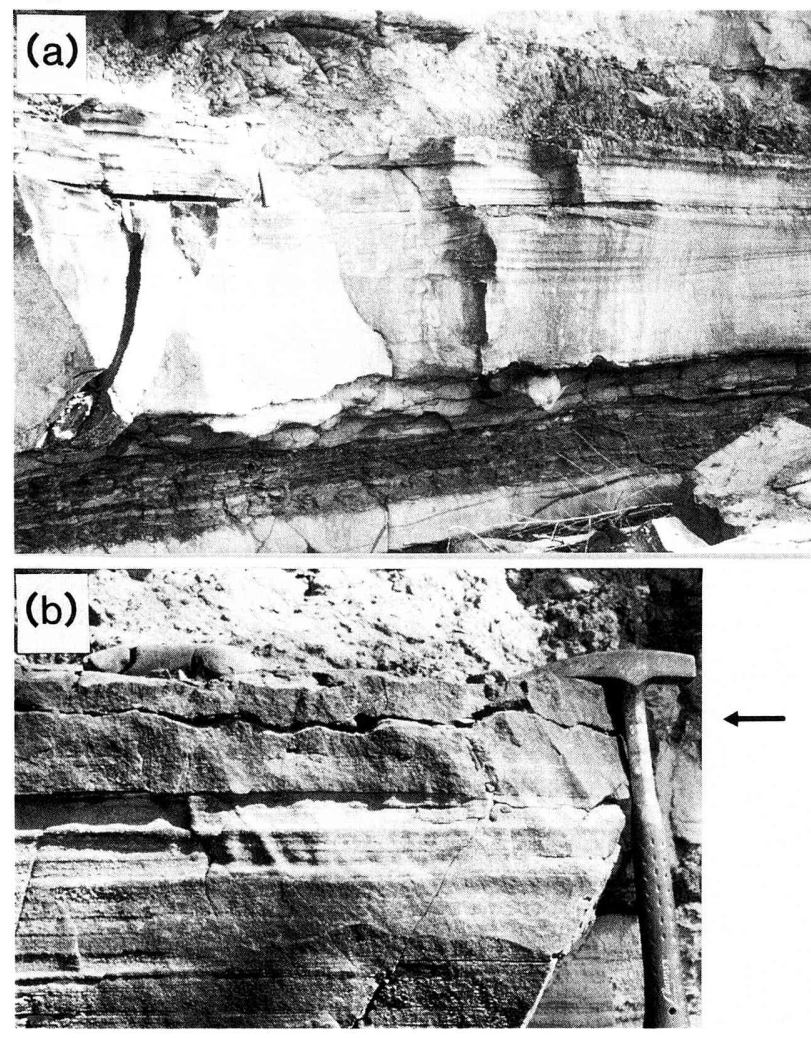

Fig. 23. Combined-flow ripples in a 'hummocky sequence' of the Miocene Shirahama Formation, Tanabe, Wakayama, Japan. (a) A discrete HCS sandstone bed intercalated by mudstone. Combined-flow ripples are located on the top of the HCS bed. The hummer as scale. (b) Close-up of the combined-flow ripples (horizon with an arrow).
$\mathrm{S} 1$ - S5 members, and is composed of storm deposits (S1, S2 members and the lower part of the S3 Member) and tidedominated shelf deposits (the upper part of the S3 and $\mathrm{S} 4$ members) (TANABE RESEARCH GROUP, 1992). Stratigraphic and structural studies of the Tanabe Group have been carried out by TANABE RESEARCH GROUP (1984, 1985, 1992, 1993).

The sandstone containing 'hummocky sequences' is intercalated within the mudstone which is interbedded by thin (about $1 \mathrm{~cm}$ ) storm sand sheets (Fig.23(a)). The sandstone is composed of fine-grained sand and is separated by a thin ( $1-2$ $\mathrm{cm})$ lenticular mud layer. The lower part is about 70 cm thick, in which hummocky cross-stratification 
is developed. The upper part is about $30 \mathrm{~cm}$ thick, in which parallel-lamination and ripple cross-lamination are observed. The ripples developed in the uppermost part of the sandstone (Fig.23(b); the horizon with an arrow) with wave lengths range between 6 and $9 \mathrm{~cm}$, and wave heights between 0.8 and $1.6 \mathrm{~cm}$. RSI values range from 1.14 to 1.70 , and RRI values from 0.44 to 0.70 . The asymmetric and convex-upward rounded profiles indicate that ripple formation occurred under combined flows. This 'hummocky sequence' is, therefore, interpreted as being formed by intense combined-flows. Internal structure observed here is only the lower parts of the foreset laminae. They are attached tangentially to the lower bounding surface, and their troughs are migrating, truncating the former one. These characteristics are restricted to combined-flow ripples (see Chap.2.2.3.).

Pleistocene Kioroshi Formation in Namekata Upland, Ibaraki. Fig.24 is another example of a storm deposit containing a 'hummocky sequence' in the upper Pleistocene Kioroshi Formation, Shimosa Group (KATSURA et al., 1985; OKAZAKI and MASUDA, 1992) in Sakihama, Dejima Upland, Ibaraki, central Japan. Hummocky cross-stratified very fine sand layers amalgamate with $10-30 \mathrm{~cm}$

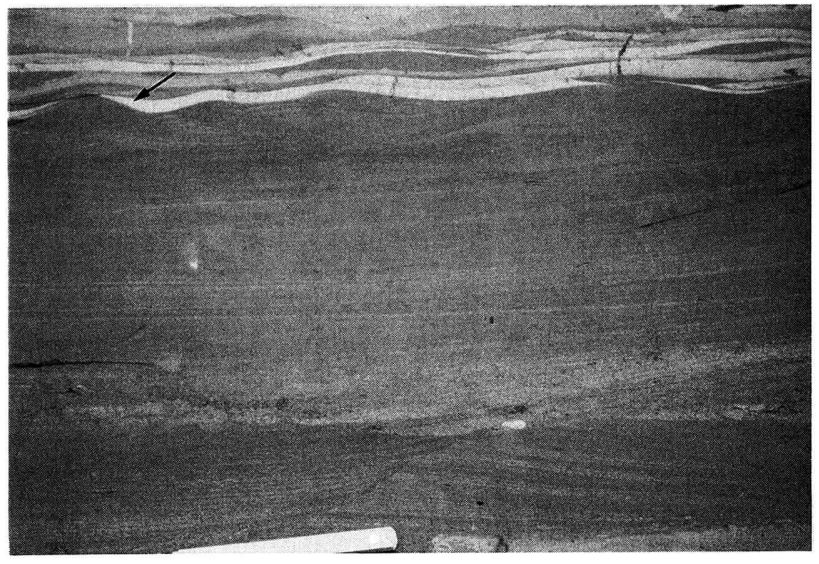

Fig. 24. Combined-flow ripples located at the top of a 'hummocky sequence'. Shoreface deposits of the Pleistocene Kioroshi Formation, Sakihama, Dejima Upland, Ibaraki, Japan. The HCS beds and ripples are composed of very fine sand. Mud-capped ripples (including one with an arrow) show the characteristics of combinedflow ripples. The scale is $20 \mathrm{~cm}$ long. thick units. The HCS or parallel-lamination is continually changing in ripple cross-lamination. The mud-capped outer forms of the ripples show convexupward rounded shapes, indicating ripple formation by combined-flow. For an example, the ripple in the upper left of Figure 24 (an arrow) has the wave length: $11.4 \mathrm{~cm}$; wave height: $2.1 \mathrm{~cm}$; RSI: 1.00 ; and RRI: 0.58, indicating the formation under combined flows. The internal structures of the ripples are discordant with the outer forms.

\subsection{Combined-Flow Ripples with Tidal Sand Waves: The Miocene Shirahama Formation in the Kii Peninsula}

Tide-dominated shelf deposits occupy the upper part of S3, S4, and S5 members of the Shirahama Formation, the lower Miocene Tanabe Group (TANABE RESEARCH GROUP, 1992). The upper part of the S3 and S4 members of the Shirahama Formation consist mainly of a mud-layer-dominated alternation of sandstone and mudstone, a sand-layer-dominated alternation, sandstone, and pebbly sandstone. The coarse-grained sandstones $10-150 \mathrm{~cm}$ thick contain largescale tabular cross-stratification, whose coset height is $10-100 \mathrm{~cm}$ (TANABE 


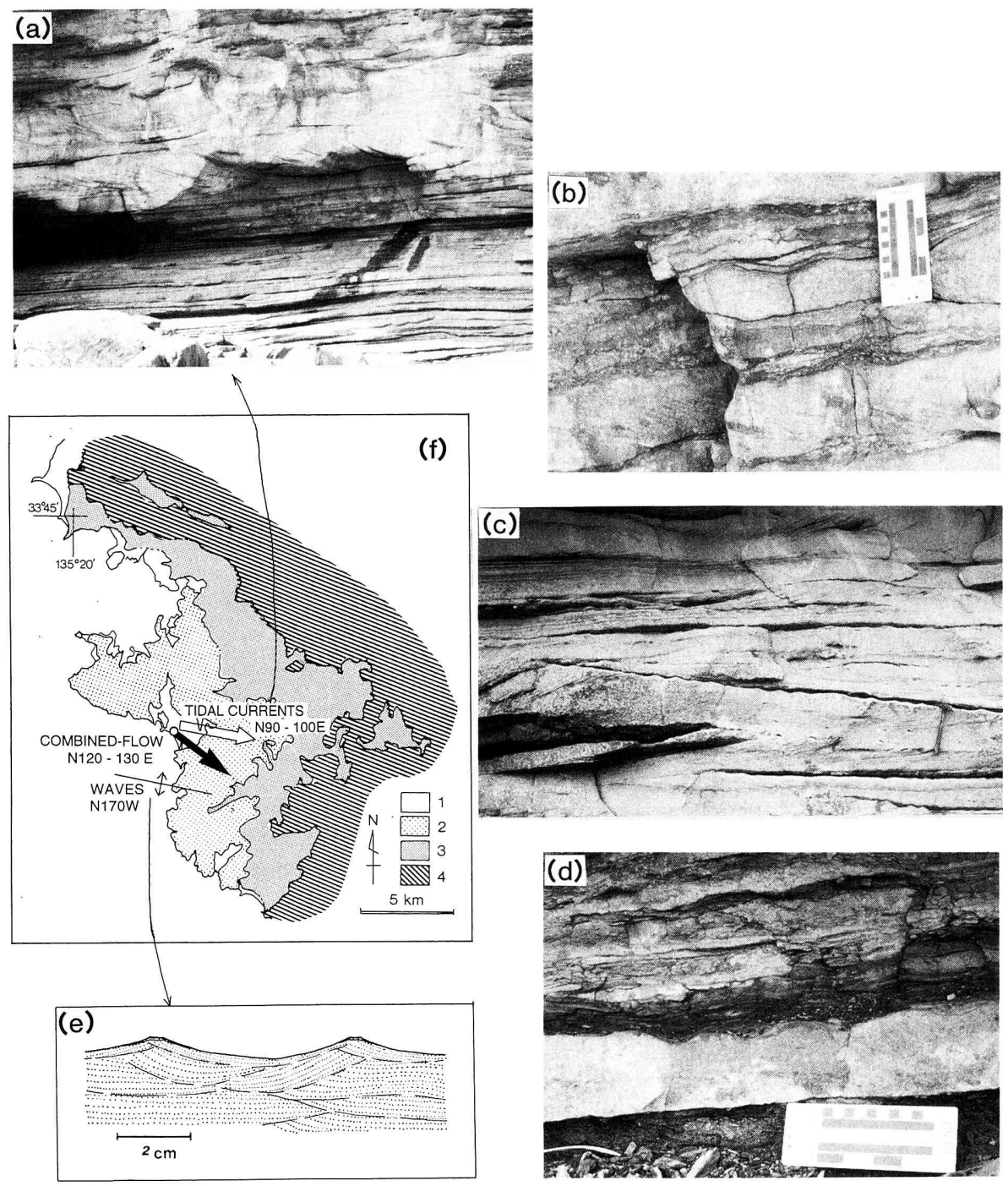

Fig. 25. (a) Tidal sand wave deposits of a shelf environment, the Miocene Shirahama Formation, Shirahama, Wakayama, Japan. The outcrop is ca. $10 \mathrm{~m}$ high. (b) Combined-flow ripples superimposed on the foreset of the tidal sand wave. The scale is $10 \mathrm{~cm}$. (c) Combined-flow ripples (hummer-stuck horizon) superimposed on the topset of the tidal sand wave. The hummer as scale. (d) Combined-flow ripples on the bottomset of the tidal sand wave. The scale is $10 \mathrm{~cm}$. (e) A trace of wave ripples occur near the tidal sand wave deposits. (f) Paleocurrents written in a geological map of the Tanabe Group (rewritten from TANABE RESEARCH GRoup, 1984). 1: Holocene, 2: The Shirahama Formation, 3: The Asso Formation, 4: basements. Arrows show paleocurrents. See text.

RESEARCH GROUP, 1985). Those cross-stratification shows a systematic change of width between each lamination; i.e., 'bundle sequences' (e.g., NIO and YANG, 1989) (Fig.25(a)). In addition, some characteristics of tidal deposits such as herringbone structures, and mud drapes are found in the sandstones. The top surfaces of these thicker sandstones often show ripple forms with a wave length of about $10 \mathrm{~cm}$ 
(Fig.25(c)). The relatively thin sandstones $(1-10 \mathrm{~cm}$ thick) intercalated within the mudstones are composed of fine- to medium-grained sand which contains well developed ripple cross-lamination (Fig.25(d)). The mudstones contain parallellaminae. Trace fossils of Spongia shikokuensis and of Nankaites kochiensis often observed in the sandstones, indicating a shelf depositional environment (TANABE RESEARCH GROUP, 1985). The thick sandstones with large-scale tabular crossstratification are thus interpreted as being cores of sand waves formed by tidal currents, and the alternations as deposits of bottomsets of the sandwaves and surrounding shelf floors.

The ripples which developed on the top surface of the thick sandstones are superimposed on the topsets or foresets of the sand waves (Figs.25(b) and (c)). The wave lengths of the ripples (Fig.25(c); the hummer-stuck horizon) range from $12.0 \mathrm{~cm}$ to $13.0 \mathrm{~cm}$, and wave heights from $1.1 \mathrm{~cm}$ to $1.9 \mathrm{~cm}$. RSI values range between 1.16 and 1.97, and RRI values between 0.51 and 0.65 . They have convexupward lee and stoss sides and rounded profiles, and can be recognized as combined-flow ripples. They may be formed by combined waning tidal currents which formed the sand waves and waves, or by other combined flows which cannot move the sand waves but are able to remove the surface sediments. The former process is more likely because the internal structures of the ripples are continuous to those of the sand waves; no gaps are found. The ripples on the relatively thin $(5-20 \mathrm{~cm})$ sandstones show more rounded profiles (Fig.25(b)). The wave lengths are $15.6 \mathrm{~cm}$ and $8.6 \mathrm{~cm}$, and wave heights are $2.4 \mathrm{~cm}$ and $0.8 \mathrm{~cm}$. RSI values are 1.0 and 1.27 , and RRI values are 0.55 and 0.52 . The internal structure is concordant with the outer form of the ripples, mainly consisting of foreset laminae. Almost all the ripples in the thin sandstones $(1-10 \mathrm{~cm}$ thick intercalated within the mudstones show well rounded profiles (Fig.25(d)). The wave lengths are $7.0 \mathrm{~cm}, 7.0 \mathrm{~cm}$ and $8.6 \mathrm{~cm}$, and wave heights are $1.0 \mathrm{~cm}, 1.1 \mathrm{~cm}$ and $1.1 \mathrm{~cm}$. RSI values are $1.17,1.26$ and 1.52 , and RRI values are $0.51,0.51$ and 0.65 . These ripples are interpreted as combined-flow ripples. On the other hand, typical wave ripples, which have high symmetry, sharp and continuous crests, and concave-upward slopes, are rarely observed in the sandstone within the alternation (Fig.25(e)).

The paleocurrent system estimated by these tidal sandwaves, combined-flow ripples and wave ripples is revealed as follows (Fig.25(f)): The tidal currents, which formed the core of the sandwaves, flow from west to east (N90 - 100E) as estimated by the dipping direction of the large-scale tabular cross-stratification. The waves might oscillate in a north - south direction, estimated from the crest axes $(\mathrm{N} 170 \mathrm{~W})$ of the wave ripples. On the other hand, combined-flow ripples (crests and foreset laminae) suggest that the combined-flow moved from the northwest to southeast (N120 - 130E). This combined-flow direction can be explained by the complex of tidal currents and the onshore component of the waves.

The Tanabe Group is distributed around the Tanabe Bay, but limited at the north where the group rests unconformably upon the Eocene Otonashigawa Group. The area of the Tanabe Group might be behind the projection of basement of the Otonashigawa Group against the tidal currents flowing down to south through the Kii Strait during the depositional period of the Shirahama Formation. Tidal 
currents and ocean currents are accelerated and likely to make a turn along such a geographical projection, and deposit a sand mass where is sheltered by the projection. Such examples are given by FLEMMING $(1980,1981)$ along the southeast coast of South Africa (ocean currents), and by DAVIS et al. (1993) along the southwest coast of Florida (tidal currents). In the case of the southwest Florida inner shelf, linear sand ridges locate off Cape Romano, and tidal currents flowing along the cape form sandwaves and megaripples on the ridges. The sand wave deposits of the Shirahama Formation are also interpreted as being formed by tidal currents along the point.

\section{Concluding Remarks and Summary}

The results of the present experiments showed that combined-flow ripples had unique features on their profiles, internal sedimentary structures and grain fabrics besides HARMS' (1969) description. These features ascribe to the characteristic motion of sand particles under combined flows. The transport mechanism by combined flows differ from either purely unidirectional flows or purely oscillatory flows.

The $U_{o}-U_{u}$ plot (Fig.3) is partitioned into fields for three bed phases. In the range of flows studied $\left(\mathrm{U}_{\mathrm{o}}: 0-30.6 \mathrm{~cm} / \mathrm{sec} ; \mathrm{U}_{\mathrm{u}}: 0-44.4 \mathrm{~cm} / \mathrm{sec}\right)$ these bed phases were: no movement; wave-dominated combined-flow ripples; and current-dominated combined-flow ripples. The transitions among all these bed phases were gradual. Two types of combined-flow ripples, wave-dominated and current-dominated combined-flow ripples, were recognized based on the ripple roundness of their streamwise profiles. The current-dominated combined-flow ripples appeared when the unidirectional velocity exceeded about $19 \mathrm{~cm} / \mathrm{sec}$. Ripple symmetry index (RSI) and ripple roundness index (RRI) are useful in distinction of combined-flow ripples from either current or wave ripples. The indicative features of combinedflow ripples, which are independent to the direction of unidirectional flow, were revealed as follows: (1) Rounded lee and stoss sides, and also rounded troughs were remarkable within current-dominated combined-flow ripples. Currentdominated combined-flow ripples were recognizable by RRI greater than 0.54 . The range of the RRI from 0.54 to 0.45 included both of wave-dominated combined-flow ripples and wave ripples. It was not easy to distinguish one from the other only by their profiles. RRI less than 0.45 indicates wave ripples. Current ripples were clearly separated from combined-flow ripples and wave ripples by RSI greater than 4.0 . The roundness became stronger as relative magnitude of oscillatory velocity to unidirectional velocity $\left(\mathrm{U}_{\mathrm{o}} / \mathrm{U}_{\mathrm{u}}\right)$ became lower. A larger unidirectional velocity often resulted in a higher asymmetry. Even a small oscillatory component superimposed on unidirectional flow plays an important role to make the characteristic round profiles; (2) The internal sedimentary structures were characterized by convex-upward foreset laminae, the extremely sigmoidal shape of the toe, a "joined" structure, and truncated troughs, especially for current-dominated combined-flow ripples. Some of these were recognized also in the wave-dominated combined-flow ripples, whose outer forms were very close to that of wave ripples; and (3) Grain fabrics of combined-flow ripples were characterized by coexistence of preferred imbrication patterns of 
both wave and current ripples in a single foreset lamina as discussed above. The upper parts were similar to wave ripples whose grain fabric is formed by grains lifting once and then falling to the site. On the other hand, the lower parts were dominated by fabric similar to the current ripples whose grain fabric was built by an avalanche of grains. The unique round profiles of combined-flow ripples resulted from the characteristic movement of sand particles on migrating ripples. The most important phenomenon was that the vortices generated only beside the lee sides of ripples, caused by the coexistence of oscillatory and unidirectional components.

The results of the experiments were applied for the geologic records. The combined-flow ripples were identifiable by observations and analyses on indices of profiles, internal structures, and grain fabrics of ripples in sedimentary records. It was revealed that the recognition of the combined-flow ripples not only enables to estimate the physical process of the deposition more accurately, but also helps the reconstruction of the paleogeographic setting as described below.

(1) Combined-flow ripples were discriminated from wave ripples in shoreface deposits. The most powerful criterion for discrimination was the "rounded profile" of the ripple; i.e., high RRI value. Grain fabric of foreset laminae was also useful.

(2) Combined-flow ripples were commonly found in the modern and ancient intertidal or subtidal zones. They were identified by their unique features such as asymmetric profile with convex-upward rounded lee and stoss sides, convexupward foreset laminae, and truncated troughs. The characteristic rounded profiles can be distinguished from the secondary deformations of the ripples by lowering water levels.

(3) Coarse-grained ripples in transgressive shoreface, which have been interpreted as products of waves, sometimes have combined-flow-origin features, such as slightly convex-upward stoss sides and foreset laminae associated with truncated troughs. It was not easy, however, to distinguish from wave ripples in this case, because more than half of RRI values of the present examples fell into the coexistence category of wave-dominated combined-flow ripples and wave ripples.

(4) Ripples which occur in 'hummocky sequences' of Pleistocene Shimosa Group were examined by the experimental results, and some ripples showed the unique features of the combined-flow ripples. The recognition of the combinedflow ripples in 'hummocky sequences' may strongly indicates the process of HCS formation, which is still a matter of controversy.

(5) The paleocurrent analysis was carried out for the tide-dominated shelf deposits including tidal sandwaves, combined-flow ripples, wave ripples and shelf mud, of the lower Miocene Shirahama Formation in Kii Peninsula, Japan. The analysis showed that the confounder of combined-flow ripples with wave ripples may provide inadequate paleoshoreline reconstruction. Therefore, the discrimination of combined-flow ripples is indispensable for the reconstruction of paleogeographical settings. 


\section{Acknowledgements}

This article is mainly composed of my Doctoral Thesis submitted to Kyushu University. I would like to express my deepest gratitude to Professor Hakuyu OKADA of Kyushu University for critical reading of the manuscript and his helpful discussions, and to Professor Fujio MASUDA of Osaka University for his precious instruction and discussions during the course of this work. I also would like to express my appreciation to Professor Tokihiko MATSUDA of Kumamoto University and Associate Professor Wonn SoH of Kyushu University for their valuable discussions, and to Professor Tsuguo SUNAMURA of University of Tsukuba for his valuable suggestions for the experimental works.

I greatly appreciate Professor Hiroshi TAKUBO of Osaka University for his advice for the experiments, and Ms. Hiromi YosHIDA and Mr. Noritaka ENDO of Osaka University for their cooperation. I also acknowledge Mr. Takahiko SAKAMOTO of Osaka Prefectural Neyagawa High School, Associate Professor Kunihiko HiSATOMI of Wakayama University, Dr. Hiroko KuMASHIRO of Natural History Museum and Institute, Chiba, Dr. Yuzo KatSuRA of Agency for Cultural Affairs and Mr. Tetsuya SAKAI of Osaka University for their discussions during the field works.

\section{References}

Allen, J.R.L. (1982): Sedimentary Structures - Their Character and Physical Basis. vol.1. Elsevier Sci.Publ.Co., Amsterdam, 593p.

ALLEN, P.A. (1985): Hummocky cross-stratification is not produced purely under progressive gravity waves. Nature, 313, 562-564.

ARNOTT, R.W. and SOUTHARD, J.B. (1990): Exploratory flow-duct experiments on combined-flow bed configurations, and some implications for interpreting storm-event stratification. Jour. Sed. Petrol., 60, 211-219.

Beardsley, R.C. and Butman, B. (1974): Circulation on the New England continental shelf: Response to strong winter storms. Geophys. Res. Lett., 1, 181-184.

BREVIK, I. and AAS, B. (1980): Flume experiment on waves and currents. I. Rippled bed. Coastal Eng., 3, 149-177.

CARLing, P.A. (1981): Sediment transport by tidal currents and waves: observations from a sandy intertidal zone (Burry Inlet, South Wales). In Nio, S.-D., ShutTenhelm, R.T.E. and VAN WeERING, Tj.C.E., eds., Holocene Marine Sedimentation in North Sea Basin. Inter.Assoc.Sed., Spec.Publ., no.5, Blackwell Sci.Publ., London, 65-80.

CHEEL, R. J. (1991): Grain fabric in hummocky cross-stratified storm beds: genetic implications. Jour. Sed. Petrol., 61, 102-110.

— and LECKIE, D.A. (1992): Coarse-grained storm beds of the Upper Cretaceous Chungo Member (Wapiabi Formation), southern Alberta, Canada. Jour. Sed. Petrol., 62, 933-945.

- and (1993): Hummocky cross-stratification. Sediment. Rev., 1, 103-122.

DApPlEs, E.C. and RomingER, J.F. (1945): Orientation analysis of fine-grained clastic sediments: a report of progress. Jour.Geol., 53, 246-261. 
Davis, R. A., Jr., Klay J. and Pliny, J. (1993): Sedimentology and stratigraphy of tidal sand ridges southwest Florida inner shelf, Jour. Sed. Petrol., 63, 91104.

DotT, R.H., Jr. and BouRGEOIS, J. (1982): Hummocky stratification: significance of its variable bedding sequences. Geol. Soc. Amer. Bull., 93, 663-680.

DukE, W.L., ARnotT, R.W.C. and CheEL, R.J. (1991): Shelf sandstones and hummocky cross-stratification: New insights on a stormy debate. Geology, 19, 625-628.

FlemminG, B.W. (1980): Sand transport and bedform patterns on the continental shelf between Durban and Port Elizabeth (southeast African continental margin), Sediment. Geol., 26, 179-206.

(1981): Factors controlling shelf sediment dispersal along the southeast African continental shelves. In NiTTROUER, C.A., ed., Sedimentary Dynamics of Continental Shelves. Mar.Geol., 42, 259-277.

— and DAVIS, R.A. Jr. (1992): Holocene evolution, morphodynamics and sedimentology of the Spiekeroog barrier island system (southern North Sea), Tidal Clastics 92 Field Guide-book. Senckenberg Institute, Germany, 32p.

GRANT, W.D. and MADSEN, O.S. (1979): Combined wave and current interaction with a rough bottom. Jour.Geophys.Res., 84, 1797-1808.

HARMS, J.C. (1969): Hydraulic significance of some sand ripples. Geol.Soc.Amer.Bull., 80, 636-396.

—, Southard, J.B., Spearing D.R. and WALKER R.G. (1975): Depositional Environments as Interpreted from Primary Sedimentary Structures and Stratification Sequences, SEPM Short Course No. 2, SEPM, Tulsa, 161p.

- - - and WALKER R.G. (1982): Structure and Sequences in Clastic Rocks. SEPM Short Course No.9, SEPM, Tulsa, 8-51p.

HIROKI, Y. and KIMIYA, K. (1990): The development of barrier-island and strandplain systems with the glacio-eustatic sea-level change in the Pleistocene Atsumi Group, central Japan. Jour.Geol.Soc.Japan, 96, 805-820. **

INMAN, D.L. and BOWEN, A.J. (1963): Flume experiments on sand transport by waves and currents. Proc. 8th Conf. on Coastal Eng., 137-150.

JennetTe, D.C. and PRYOR, W.A. (1993): Cyclic alternation of proximal and distal storm facies: Kope and Fairview formations (upper Ordovician), Ohio and Kentucky. Jour.Sed.Petrol., 63, 183-203.

Katsura, Y., Masuda, F. and Obata, I. (1984): Storm-dominated shelf sea from the Lower Cretaceous Choshi Group, Japan. Ann.Rep., Inst.Geosci., Univ.Tsukuba, no.10, 92-95.

- Masuda, F., OKaZAKI, H. and MaKino, Y. (1985): Storm deposits developed in the Pleistocene strata around the Tsukuba Upland. Tsukuba Environ. Studies, Univ. Tsukuba, no.9, 54-60.*

Kishi, S., Nishimura, M. and HoyanaGi, K. (1992): Response of delta system to sea-level changes, Pleistocene Usagidani Formation in Niitsu Hills. Abst. 99th Ann.Meeting Geol.Soc.Japan, 271.*

LECKIE, D.A. (1988): Wave-formed, coarse-grained ripples and their relationship to hummocky cross-stratification. Jour.Sed.Petrol., 58, 607-622. and KRYSTINIK, L.F. (1989): Is there evidence for geostrophic currents preserved in the sedimentary record of inner to middle-shelf deposits? 
Jour.Sed.Petrol., 59, 862-870.

Makino, Y. and Masuda, F. (1986a): Wave ripples in the Pleistocene PaleoTokyo Bay. Jour.Georga.Soc.Japan, 95, 241-253.**

and - (1986b): Wave dunes in the Pleistocene Narita Formation in the Northeast Coast of Lake Kasumigaura, Central Japan. Sci.Rep., Dep.Educ., Ibaraki Univ., no.35, 73-84.*

MASudA, F. (1993): The Osaka Group and relative sea-level change. Prof. T. Shiki, Memor.Vol., "Event and Rhythm", CHIKYU Monthly, 86-94."

and MAKINO, Y. (1987): Paleo-wave condition reconstructed from ripples in the Pleistocene Paleo-Tokyo Bay deposits. Jour. Geogra. Soc. Japan, 96, 2345 . $^{* *}$

and SUZAKI, K. (1984): Oriented thin section unconsolidated loose sands and its sedimentological significance. Bull.Environ.Res.Cen., no.8, 17-28.*

and YoKoKawa, M. (1992): Combined-flow ripples produced by flume experiments. Sci.Rep., Col.Gen.Educ. Osaka Univ., 41, 1-13.

and (1993): Combined-flow ripple profiles: A preliminary note. Jour.Sed.Soc.Japan, no.38, 107-111.**

MrtamurA, M. (1992): Stratigraphy and geologic structure of the Osaka Group (Pliocene and Pleistocene) in Keihanna Hills, Kinki District, Japan. Quat.Res.(Daiyonki-Kenkyu), 31, 159-177.**

Murakoshi, N. and MASUdA, F. (1991): A depositional model for a flood-tidal delta and washover sands in the late Pleistocene Paleo-Tokyo Bay, Japan. In Smith, D.G., Reinson, G.E., Zaitlin, B.A. and Rahmani, R.A., eds., Clastic Tidal Sedimentology. Can.Soc.Petrol. Geol., Mem.16, 219-226.

and - (1992): Estuarine, barrier-island to strand-plain sequence and related ravinement surface developed during the last interglacial in the Paleo-Tokyo Bay, Japan. Sediment.Geol., 80, 167-184.

MurRAY, S.P., 1970, Bottom currents near the coast during Hurricane Camille. Jour.Geophy.Res., 75, 4579-4582.

MYrow, P.M. (1992): Bypass tempestite facies model and proximality trends for an ancient muddy shoreline and shelf. Jour.Sed.Petrol., 62, 99-115. and Southard, J.B. (1991): Combined-flow model for vertical stratification sequences in shallow marine storm-deposited beds. Jour.Sed.Petrol., 61, 202210.

NIEDORODA, A.W. and SWIFT, D.J.P. (1981): Maintenance of the shoreface by wave orbital currents and mean flow: Observations from the Long Island coast. Geophys.Res.Lett., 8, 337-340.

NIO, S.D. and YANG, C.S. (1989): Recognition of Tidally-Influenced Facies and Environments. International Geoservices BV, Short Course Note Ser. no. 1, Netherlands, 230p.

NøTTVEDT, A. and KREISA, R.D. (1987): Model for the combined-flow origin of hummocky cross-stratification, Geology, 15, 357-361.

OKAZAKI, H. and MASUDA, F. (1989): Arcuate and bird's foot deltas in the Pleistocene Paleo-Tokyo Bay. In WhAteley, M.K.G. and PiCKERING, K.T., eds., Deltas: Sites and Traps for Fossil Fuels. Geol.Soc.Spec. Publ., no.41, 129-138.

and (1992): Depositional systems of the Late Pleistocene sediments in 
Paleo-Tokyo Bay area. Jour.Geol.Soc.Japan, 98, 235-258.**

REINECK, H.-E. and SINGH, I.B., 1980, Depositional Sedimentary Environments. 2nd.ed., Springer-Verlag, Berlin, 549p.

Sakamoto, T., Yokoi, S., Yoshimura, K. and FujioKa, T. (1991): Marine sandy sediments in the Osaka Group: Sedimentary facies in Neyagawa City and its vicinities. Jour.Sed.Soc.Japan, no.35, 101-108.*

SHIPEK, C.J. (1962): Photographic survey of sea floor on southwest slope of Eniwetok Atoll. Geol.Soc.Amer.Bull., 73, 805-812.

SInGH, I.B., 1980, The Bijaigarh Shale, Vindhyan System (Precambrian), India An example of a lagoonal deposit. Sediment.Geol., 25, 83-103.

Somekawa, H. and Yoshikawa, S. (1983): The Osaka Group in the Tanabe Hills, Kyoto Prefecture, Japan. Earth Sci. (Chikyu Kagaku), 37, 98-109.**

Southard, J.B., Lambie, J.M., Federico, D.C., Pile, H.T. and Weidman, C.R. (1990): Experiments on bed configurations in fine sands under bidirectional purely oscillatory flow, and the origin of hummocky cross-stratification. Jour.Sed.Petrol., 60, 1-17.

SWAN, C. (1990): An experimental study of waves on a strongly sheared current profile. Proc. 22nd. Coast. Engen. Confer., Amer.Soc.Civ. Engen., 489-502.

SwifT, D.J.P., Figueiredo, A.G.,Jr., FreEland, G.L. and OERTEL, G.F. (1983): Hummocky cross-stratification and megaripples; a geological double standard? Jour.Sed.Petrol., 53, no.4, 1295-1317.

TANABE RESEARCH GROUP (1984): Stratigraphy and geological structure of the Tanabe Group in the Kii Peninsula, Southwest Japan. Earth Sci. (Chikyu Kagaku), 38, 249-263.**

(1985): Tanabe Group in the Western Coastal Region (Hiki-Kamoi Area) of the Kii Peninsula, Sci.Rep., Dep.Educ., Wakayama Univ., no.34, 3-24.**

(1992): Sedimentary facies and stratigraphy of the Asso Formation -Study on the Asso Formation, Tanabe Group (Part 1)-, Earth Sci. (Chikyu Kagaku), 46, 369-383.**

(1993): Sedimentary facies and sedimentary environments of the Shimomisu fan-delta, -Study on the Asso Formation, Tanabe Group (Part 2) -. Earth Sci. (Chikyu Kagaku), 47, 1-16.**

TANKARD, A.J. and HOBDAY, D.K. (1977): Tide-dominated back-barrier sedimentation, early Ordovician Cape Basin, Cape Peninsula, south Africa. Sediment.Geol., 18, 135-159.

TANNER, W.F. (1967): Ripple mark indices and their uses. Sedimentology, 9, 89104.

Vos, R.G. and ERIKSSON, K.A. (1977): An embayment model for tidal and wave swash deposits occurring within a fluvially dominated middle proterozoic sequence in south Africa. Sediment.Geol., 18, 161-173.

WUNDERLICH, F. (1970): Genesis and environment of the "Nellenkopfchenschichten" (Lower Emsian, Rheinian Devon) at locus typicus in comparison with modern coastal environment of the German Bay. Jour.Sed.Petrol., 40, 102-130.

YoKoKAWA, M. and MASUDA, F. (1988): Sampling and consolidating techniques used in grain fabric analysis of recent foreshore deposits. Bull. Environ. Res.Cen., Univ. Tsukuba, no.12, 31-36.* 
- and (1990): An experimental study on the relationship between grain fabric and flow types, Bull.Environ.Res.Cen., Univ. Tsukuba, no.14, 91-98.* and (1991): Grain fabric of hummocky cross-stratification. Jour.Geol.Soc.Japan, 97, 909-916.

- - - and ENDO, N. (1995): Sand particle movement on migrating combinedflow ripples. Jour. Sed. Res., A65, 40-44.

$*$ in Japanese

** in Japanese with English abstract 